Universidad de Lima

Facultad de Ciencias Empresariales y Económicas

Carrera de Economía

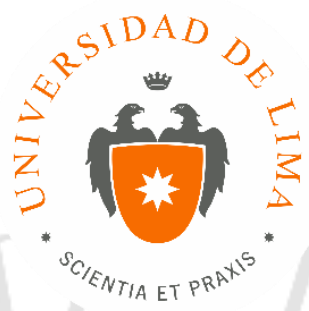

\title{
ANÁLISIS DE LA IMPORTANCIA DE COBERTURA CAMBIARIA MEDIANTE FORWARDS PARA EMPRESAS PERUANAS 2015-2018
}

Trabajo de suficiencia profesional para optar el Título Profesional de Economista

Sustentación de caso

Daniel Elias Ugarte

Código 20100375

Asesor

Abelardo Humberto Lara Vassallo

Lima - Perú

Diciembre de 2018 







\section{ANÁLISIS DE LA IMPORTANCIA DE COBERTURA CAMBIARIA MEDIANTE FORWARDS PARA EMPRESAS PERUANAS \\ 2015-2018}




\section{TABLA DE CONTENIDO}

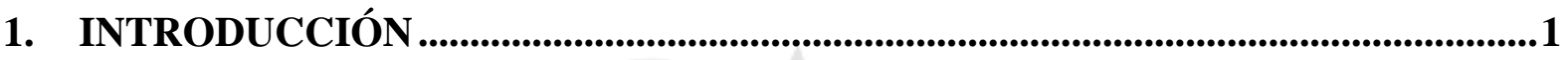

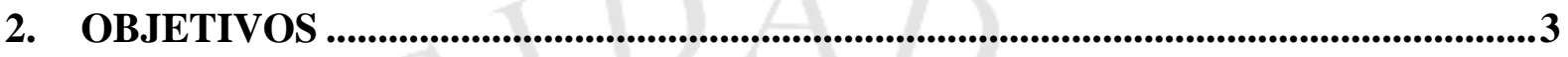

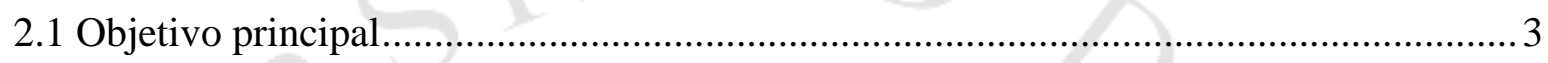

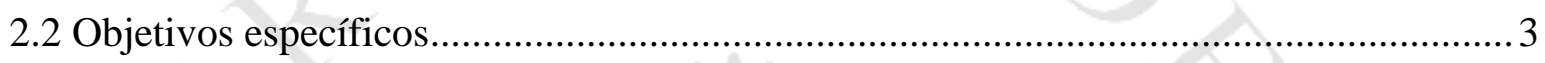

3. PREGUNTAS DE INVESTIGACIÓN ...........................................................................4

4. METODOLOGÍA DE RECOLECCIÓN DE LA INFORMACIÓN.............................5

5. METODOLOGÍA DE ANÁLISIS DE LA INFORMACIÓN ..................................6

6. DESCRIPCIÓN DEL CASO ......................................................................................

7. ANÁLISIS Y DISCUSION DE RESULTADOS...........................................................21

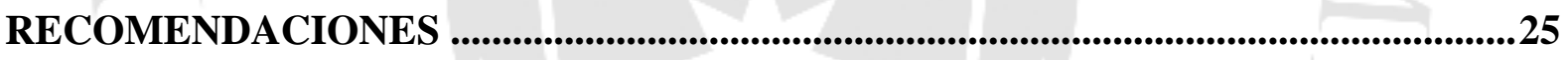

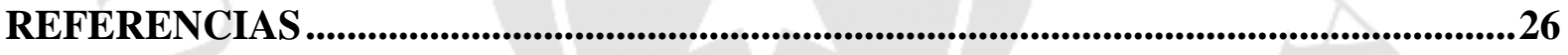

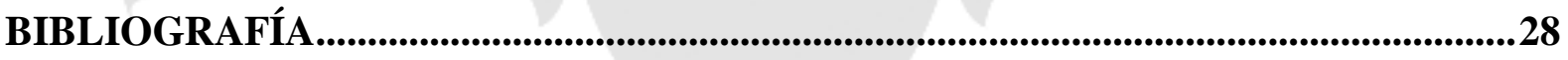




\section{ÍNDICE DE TABLAS}

Tabla 6.1 Riesgo equivalente de los instrumentos financieros derivados en M.E.................. 12

Tabla 6.2 Ratio diferencia de tipo de cambio / utilidad operativa .......................................... 18

Tabla 7.1 Ejemplo I: Forward de empresa minera, 2018 ….............................................21

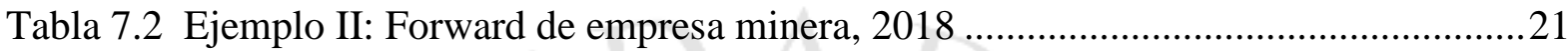

Tabla 7.3 Ejemplo III: Forward de empresa petrolera, 2018 …..............................................22 


\section{ÍNDICE DE FIGURAS}

Figura 6.1 Total posición bruta de forwards, 2001-2017.................................................. 10

Figura 6.2 Participación de forwards de los 5 bancos principales, 2005-2017..................... 11



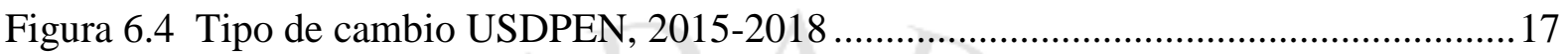




\section{ÍNDICE DE ANEXOS}

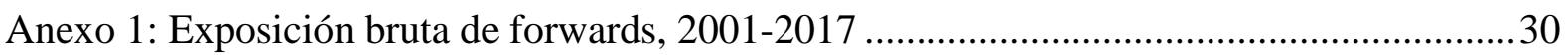

Anexo 2: Utilidad operativa de empresas listadas en la SMV, 2015 - 2018 ........................... 32

Anexo 3: Diferencia de cambio neto de empresas listadas en la SMV, 2015 - 2018 .............. 34

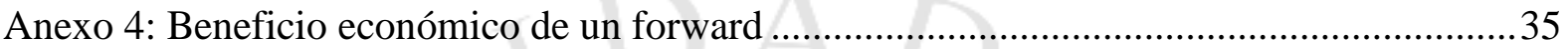




\section{INTRODUCCIÓN}

Las empresas intentan enfocar sus esfuerzos en lograr un mayor nivel de eficiencia en su cadena productiva que genere mejores márgenes y por ende buscan maximizar el valor de la firma. Sin embargo, en muchas empresas, al no ser el foco de negocio, descuidan o no le toman el interés necesario a la variable de riesgo cambiario que se puede presentar en su balance al tener activos o pasivos en moneda extranjera. El Banco Central de Reserva del Perú (BCRP, 2006) menciona su importancia e indica que, el sector empresarial peruano mantiene niveles importantes de deuda en dólares, por tanto, es relevante tomar en cuenta el efecto hoja de balance, ya que una variación relativa de las monedas tiene un impacto directo en la deuda de las empresas y que explícitamente un incremento del tipo de cambio nominal genera un perjuicio financiero (p.1). Este factor es muy frecuente y fundamental en el Perú, dado que a pesar de que la dolarización ha presentado una tendencia a la baja durante las últimas 2 décadas, aún nos encontramos en niveles por encima de los estándares internacionales. (Contreras, Martínez, Quispe, Regalado, 2017, p.2).

La mayoría de empresas corporativas tienen equipos de tesorería y control de riesgos para evaluar las técnicas de cobertura cambiaria por la importancia de esta variable, sin embargo, esto no sucede necesariamente o no es bien manejado conforme la empresa tiene un menor tamaño y puesto que sus márgenes son menores, están enfocados en obtener rentabilidad por el propio giro de negocio.

El presente estudio es importante para la mayoría de la sociedad empresarial y busca enfatizar que el riesgo de moneda en el balance de resultados no debería ser una variable exógena en la gestión de decisiones de la empresa. El riesgo cambiario puede significar, en caso de no tener coberturas cambiarias, una pérdida directa en los flujos de las empresas dependiendo de la diferencia en los niveles de sus activos y pasivos en moneda extranjera. A pesar que la realidad peruana nos hace notar que nuestro mercado de capitales y estructura de coberturas mediante derivados financieros se encuentra en un estado incipiente aún, se busca constantemente promocionar e impulsar su uso y por lo tanto se presenta una recomendación a las empresas peruanas para mitigar el riesgo mediante el derivado financiero, forward de monedas. 
Según el estudio realizado por el BBVA Continental (BBVA, 2007) una de las razones por las que no se utilizan los derivados financieros es principalmente por falta de capacitación y por ello, para buscar un desarrollo eficiente se debe impulsar los instrumentos financieros básicos, difundir su uso para usuarios y mostrar reglas de juego con una normativa tributaria y contable clara. (p.10)

En el presente estudio, se mostrarán un conjunto las empresas peruanas que cotizan en la Bolsa de Valores de Lima, de diferentes sectores, para ver el efecto de la diferencia de cambio, su impacto en la utilidad operativa y el actual mercado de derivados financieros en la economía peruana. 


\section{OBJETIVOS}

\subsection{Objetivo principal}

- El objetivo principal de este caso de estudio es resaltar la importancia de tomar cobertura del tipo de cambio para evitar pérdidas cambiarias que afecten el balance de resultados mediante el derivado financiero forward de moneda.

\subsection{Objetivos específicos}

- Contrastar la importancia de los forwards de moneda como opción de cobertura para empresas peruanas.

- Demostrar la profundidad del mercado de forwards en la economía peruana y su desagregación por sectores, agentes económicos que intervienen y tipologías de cobertura.

- Evaluar la evolución del tipo de cambio dólar/sol y su impacto en los estados financieros de las empresas peruanas listadas en la Bolsa de Valores de Lima durante el año 2015 al 2018.

- Detallar el manejo de coberturas de forwards de 02 empresas con descalce de moneda que tomaron coberturas con el Banco Interamericano de Finanzas. 


\section{PREGUNTAS DE INVESTIGACIÓN}

¿Es importante tomar los forwards de moneda como cobertura de riesgo de cambio para las empresas peruanas?

¿Cuántas empresas utilizan el mercado de forwards a nivel bancario actualmente y con qué finalidad lo utilizan?

¿La economía peruana está tomando las suficientes coberturas para evitar la volatilidad de tipo de cambio?

¿Cómo se ha comportado el tipo de cambio dólar/sol y cómo ha afectado a las empresas peruanas?

¿Qué aspectos se deben tomar en cuenta y como se calcula el derivado financiero conocido como forward?

¿Cuáles son los requisitos para obtener una línea de forward y que es el riesgo equivalente?

¿Qué factores afectan el TC? 


\section{METODOLOGÍA DE RECOLECCIÓN DE LA INFORMACIÓN}

Para realizar el análisis de la información en el estudio presente, se seguirá una serie de pasos según se detalla a continuación:

Se descargará la estadística de tipo de cambio dólar vs sol de la fuente Bloomberg, filtrando la serie con una periodicidad trimestral desde inicios del 2015 hasta el segundo trimestre del 2018 para observar la tendencia de esta variable a lo largo del periodo de estudio.

Además, se obtuvieron datos de la Superintendencia de Banca y Seguros (SBS), dentro de las estadísticas de la Banca múltiple del sistema financiero, las operaciones forwards de manera mensual, de tal forma que se ve el crecimiento del mercado en los derivados financieros y por otro lado, se filtró la información por cada banco con el fin de precisar la posición individual de cada banco que participa como contraparte de coberturas.

Se buscó adicionalmente, extraer datos precisos de la Superintendencia de Mercado de Valores (SMV) para investigar la información financiera de un grupo de 53 empresas que están listadas en la Bolsa de Valores de Lima y para el periodo del 2015 hasta mediados del 2018, descargar sus Estados Financieros trimestrales para revisar su utilidad operativa y diferencias de cambio neto en el Estado de Resultados y de esta forma mostrar el grado de importancia en el accionar empresarial.

Por último, se consiguió la base de datos del Banco Interamericano de Finanzas (BANBIF), donde se analizan dos empresas puntualmente para aterrizar el objetivo planteado y mediante las cuales servirán para mostrar el manejo y resultado logrado en la toma de decisiones al tomar coberturas de tipo de cambio. 


\section{METODOLOGÍA DE ANÁLISIS DE LA INFORMACIÓN}

En primer lugar, se utilizarán gráficos descriptivos para analizar la evolución, en los últimos 18 años, la posición bruta de forwards en el mercado peruano para hacer notar el proceso de cambio exponencial que ha tenido el mercado de derivados en nuestro país emergente. Además, se tendrá otro gráfico, donde se apreciará la concentración actual del mercado y el grado de participación de mercado de los 5 principales bancos y su evolución en los últimos años.

Asimismo, mediante combinación estadística y casuística se analizará el beneficio o pérdida económica que puede resultar al cerrar un contrato a futuro de monedas además de observar los posibles impactos en las empresas que ha tenido el tipo de cambio desde el 2015 hasta el segundo semestre del 2018 y como se hubieran podido mitigar.

Los Estados financieros de 53 empresas descargados de la Superintendencia de Mercado de Valores nos servirán para analizar los resultados mediante el ratio de pérdida o ganancia por diferencia de cambio y cuanto representan de la utilidad operativa del negocio que es fundamental para notificar si es relevante realizar este caso de estudio. Específicamente se mostrará el detalle de empresas del sector económico minero, en donde se examinarán las exposiciones al riesgo cambiario que se manejan en esta industria y como cada empresa tiene un mecanismo de acción distinto en cuanto al manejo del tipo de cambio.

Una vez detallados los principales factores que afectan el tipo de cambio, se mencionaran sobre su impacto sobre el tipo de cambio nominal, así como las intervenciones del ente regulador se pueden tomar e identificar como efecto sobre el tipo de cambio y posteriormente llevar a cabo la indagación del presente estudio, en cuanto a la importancia de cobertura cambiario mediante forwards; se realizará una comparación entre las empresas que han realizado coberturas de tipo de cambio con el Banco interamericano de Finanzas y el hecho de estar sin acción ante un riesgo cambiario en la empresa. 


\section{DESCRIPCIÓN DEL CASO}

Se ha analizado a las empresas peruanas que hayan tomado cobertura de forwards de moneda durante los años 2015 al 2018, para ver la evolución de las mismas en el mercado financiero, observar que relación guardan con los efectos político-económicos, al mismo tiempo observar que beneficio económico han conseguido, en caso así lo fuese, y para el caso de las empresas que hayan cerrado derivados de monedas con el Banco Interamericano de Finanzas específicamente, ver si hubo una gestión eficiente ante un descalce entre los activos y pasivos de la empresa. Se busca analizar si con el derivado financiero forward de moneda se llega a mitigar el riesgo cambiario y también culturizar al lector y darle pie a que el riesgo cambiario se encuentra latente y es un factor esencial a tomar en consideración para no afectar los resultados en una empresa. Por tal motivo, es fundamental identificarlo y saber qué tipos de cobertura son posibles de adquirir, así como que requisitos y restricciones tiene el sistema financiero y que contrapartes se encuentran habilitados en el mercado peruano para otorgar coberturas.

Según Papaioannou, existen tres fuentes de riesgos que se presentan en las compañías; el riesgo transaccional en el corto plazo, referido a operaciones en moneda extranjera donde al momento de realizar el pago al vencimiento, este se ve afectado por la variación en el periodo transcurrido. El riesgo económico en el largo plazo, donde la volatilidad cambiaria afecta los ingresos y costos de la compañía y, por último, el riesgo de traslación, ocurrido cuando las empresas tienen su casa matriz en otros países y al momento de consolidar los balances financieros están sujetos al tipo de cambio de dicho momento (como se citó en Chang, 2013, p. 2).

Según la Fisanotti (2014), los primeros derivados financieros fueron contratos sobre bienes agrícolas y metálicos gracias a la creación de la "The Chicago Board of Trade" en 1848 y ya en los años 1970 toma relevancia la cobertura de derivados sobre activos financieros como tasas de interés y monedas (p.16). El BCRP (2014) define a los derivados financieros como acuerdos bilaterales, con precios basados en otros activos de referencia conocidos como activos subyacentes con los cuales se pueden utilizar como instrumentos de cobertura de riesgos (p.1). Son regulados por la Superintendencia de Banca, Seguros y AFP con la Ley 26702 publicada en diciembre del 2008. Los Forwards de divisas han tomado una importante relevancia en los últimos años, gracias a los bancos 
centrales, quienes incitan a una correcta administración de riesgos mediante esta vía y por lo cual buscamos analizar si realmente tiene un efecto positivo.

Estos forwards, consisten en un acuerdo de dos partes que mediante contrato pactan un tipo de cambio en una fecha determinada; presentan la ventaja de ser a la medida del solicitante. Según Hull (2009), los forwards de moneda, son derivados financieros que cotizan en un mercado no regulado, conocido como over-the-counter, vinculados por teléfono y/o computadora, sin reunirse físicamente y entre dos agentes económicos, uno de ellos siendo una institución financiera (p.20).

Resulta fundamental conocer el cálculo del derivado financiero forward, el cual se realiza de la siguiente forma:

TC Fwd Compra $=$ TC Spot $x((1+\text { Tasa pen } \mathrm{A}) /(1+\text { Tasa usd } \mathrm{P}))^{\mathrm{n} / 360}$

TC Fwd Venta $=$ TC Spot $x((1+\text { Tasa pen } \mathrm{P}) /(1+\text { Tasa usd } \mathrm{A}))^{\mathrm{n} / 360}$

- $\quad$ TC FWD = Tipo de Cambio Forward

- $\quad$ TC Spot $=$ Tipo de Cambio Spot o actual

- $\quad$ Tasa Pen $\mathrm{A}=$ Tasa de interés activa en soles

- Tasa Pen $\mathrm{P}=$ Tasa de interés pasiva en soles

- $\quad$ Tasa Usd A = Tasa de interés activa en Moneda extranjera

- Tasa Usd $\mathrm{P}=$ Tasa de interés pasiva en Moneda extranjera

- $\quad \mathrm{N}=$ Plazo

Siempre se ancla a la institución financiera, como una entidad bancaria, como el agente que realizaría la acción del tipo de forward, por ejemplo, que en el caso de un tipo de cambio forward compra dólares, los dólares en la fecha futura serán comprados por el banco. El acuerdo puede ser con entrega de divisas al vencimiento (Full Delivery Forward) o sin entrega de divisas (Non Delivery Forward) calculado este último entre la diferencia del precio acordado y el precio promedio del día de vencimiento.

En el sistema de Bloomberg, un sistema usado internacionalmente por empresas corporativas, bancos, sociedades agentes de bolsa, administradora de fondos entre otros, se construye una curva forward donde se puede observar la curva a diferentes plazos del forward tanto para la compra como para la venta y que sirve para quienes lo adquieren, como una herramienta indicativa y bastante eficiente como otorgador de precios. 
Cabe resaltar que la razón principal por la que nacen las herramientas de cobertura y se hace sumamente importante tomarlas en consideración es por la existencia del riesgo cambiario. Según el área de estudios económicos del BCRP (2017) la economía peruana, hasta el 2017, sigue presentando un grado de dolarización financiera elevada para los estándares internacionales, cercano a 35\%, a pesar de haberse reducido considerablemente desde los años 1990 donde se encontraba en 80\% (p.3). Mantenernos en ratios elevados de dolarización genera dos necesidades, tomar consideración la exposición del riesgo y también encontrar un mercado líquido y transaccional de derivados que permita reducir la incertidumbre sobre las fluctuaciones futuras del tipo de cambio; sin embargo, la evidencia nos muestra que hasta la fecha no presentamos un mercado desarrollado, ni un público altamente capacitado a diferencia de Estados Unidos y países Europeos donde es frecuente su uso en casi todos los tamaños de compañías.

Las empresas peruanas que observan un descalce a futuro en el que tienen cuentas por pagar o en términos macro empresariales, que tienen pasivos en moneda extranjera a futuro mayores que sus activos en moneda extranjera deberán cotizar con las entidades contrapartes un forward venta y de la misma forma las empresas, principalmente exportadoras o mineras, que van a percibir una mayor cantidad de flujos en moneda distinta a la local deberán cotizar forward compra para mitigar el riesgo de cambio. Explícitamente se aplica de la siguiente forma, por ejemplo, una empresa en el sector agroexportador que tiene ingresos en moneda extranjera dado que normalmente vende a clientes del exterior y paga a proveedores locales por su mano de obra peruana, además de pago de impuestos, detracciones, compensación por tiempo de servicio, gratificaciones y otros pasivos por lo que necesita cambiar parte del flujo a moneda local, viéndose expuesto al mercado cambiario.

Se puede observar en el siguiente gráfico, que recién hace un periodo no mayor a 10 años el mercado de forwards toma un nivel relevante, aunque aún es pequeño para la totalidad de empresas que podrían llevar una gestión eficiente tomando coberturas del riesgo cambiario. 
Figura 6.1

Total posición bruta de forwards, 2001-2017

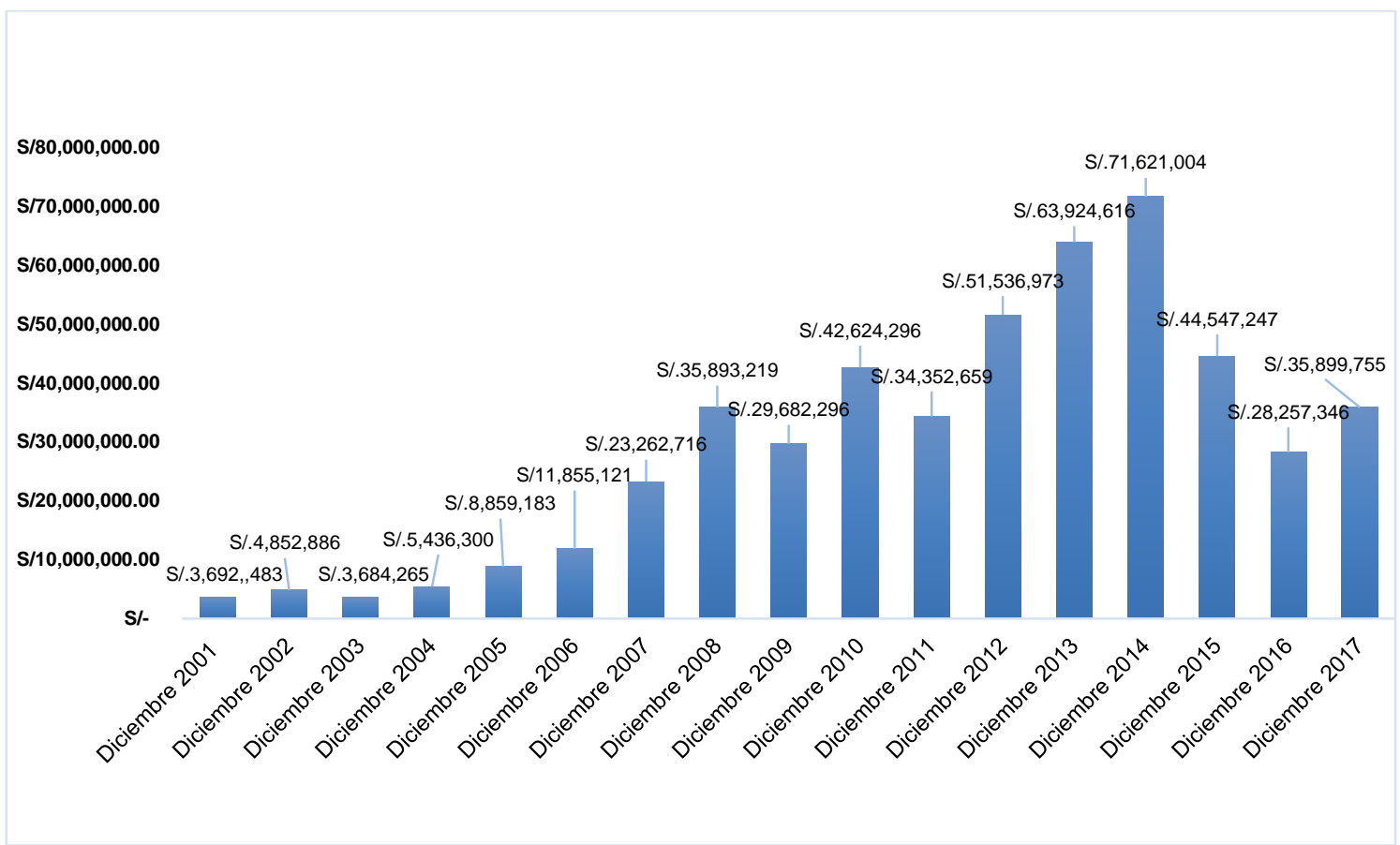

Fuente: Superintendencia de Banca, Seguros y AFP, SBS. (2018)

Elaboración Propia

A pesar de, que es un mercado mundial gigante, estos aún no representan un gran volumen, en economías emergentes como la peruana, por lo que se toma relevante estos estudios casuísticos para que un mayor grupo de empresas se inserten en el mercado de derivados.

La evidencia muestra que, de los bancos que actúan como contrapartes en el mercado local, los primeros 5 bancos han tenido una participación mayor al $80 \%$ en términos de posición bruta de forwards a lo largo del tiempo y en los últimos cinco años representan un porcentaje ligeramente cercano al $90 \%$ a pesar de que existen más de ocho bancos que pueden actuar como contrapartes. 
Figura 6.2

Participación de forwards de los 5 bancos principales, 2005-2017

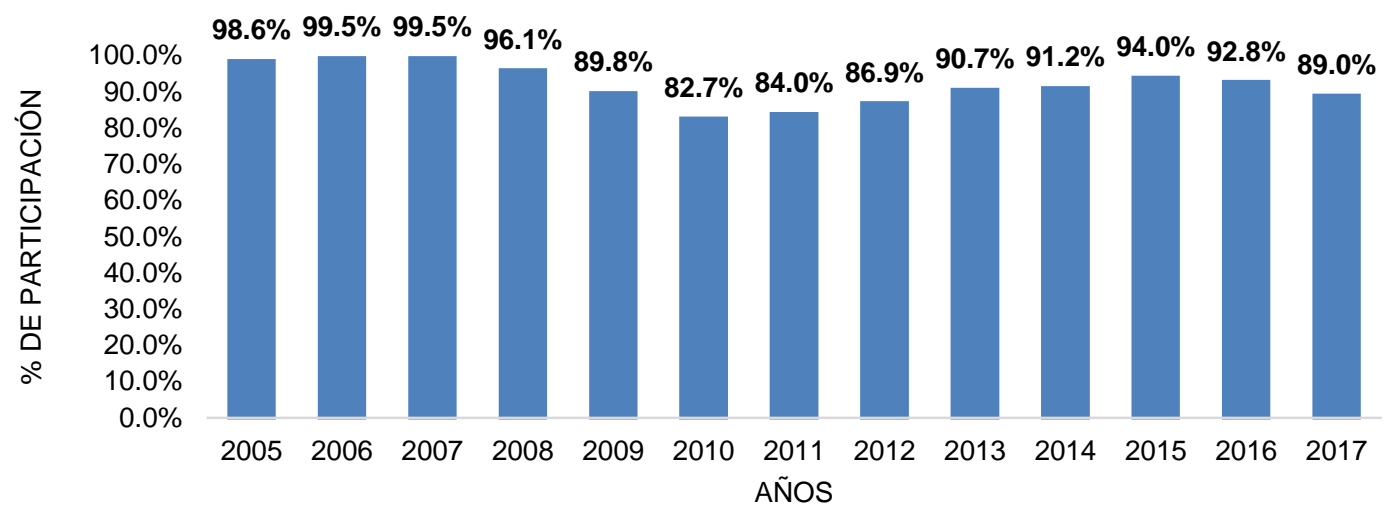

Fuente: Superintendencia de Banca, Seguros y AFP, SBS. (2018)

Elaboración Propia

Además, se debe precisar que el uso de estos derivados puede ser con tres finalidades. Primero como finalidad de cobertura de la fluctuación cambiaria dado que esta volatilidad afecte los flujos de la empresa, propósito en el cual nos estamos centrando en este caso. Las razones principales para la toma de este producto, pueden ser para asegurar un precio futuro por ejemplo en la adquisición o venta de un activo en una fecha posterior, también cubrir una posición de exportación que se va a recibir o una importación que se tenga un vencimiento de pago futuro, así también proteger las inversiones o préstamos tomados en una moneda distinta a la funcional de la misma empresa, entre otros ejemplos.

Segundo, están los especuladores, quienes ante hechos volátiles o expectativas económico financieras apuestan por tomar posiciones de compra o venta sobre un activo para buscar obtener una ganancia futura y por último los arbitrajistas que encuentran dos mercados o más con diferencia de precios en un activo y sin tomar riesgo compran y venden los mismos obteniendo una rentabilidad gracias a las ineficiencias que encontraron en los mercados.

La utilización actual de los forwards se da por instituciones bancarias, financieras, fondos de coberturas, fondos mutuos y de capital, empresas corporativas y grandes empresas, entre otros. Es importante para todas las empresas sin embargo no todas califican para tener una contraparte, en este caso los bancos, quienes otorgan una línea de crédito y en donde influye el sector donde se encuentran, ya sea industrial, minero, 
manufactura, agroindustrial, comercio, etc. Dado que no existe una garantía específica se somete a una evaluación rigurosa, donde se observa el plazo, el monto y la palanca de cobertura que tiene el banco frente a cada agente económico.

Se evidencia que los contratos de derivados forwards de moneda pueden ser utilizados por cualquier empresa siempre y cuando encuentre una institución financiera regulada y calificada, que dentro de sus parámetros la evalúe y acepte trabajar el contrato bilateral, dado que es una operación que implica un riesgo de contraparte o riesgo de crédito. Las instituciones que pueden otorgar estos derivados financieros y son los generadores de mercados o también conocidos como "Market makers", analizan la solvencia de la empresa, la necesidad de cobertura o especulación de cambio, el flujo futuro de la empresa y proceden a otorgar una línea de crédito determinada la necesidad del cliente.

La Superintendencia de Banca, Seguros y AFP (Ley N.14354, 2009) indica que para estimar el riesgo de contraparte cuando se pactan operaciones de derivados financieros, tendrán una ponderación estimada dependiendo del plazo de las operaciones y el monto. Según se detalla:

Tabla 6.1

Riesgo equivalente de los instrumentos financieros derivados en M.E

\begin{tabular}{|l|c|c|c|c|c|c|}
\hline \multirow{2}{*}{$\begin{array}{l}\text { Instrumentos } \\
\begin{array}{l}\text { Financieros } \\
\text { Derivados de M.E }\end{array}\end{array}$} & $\begin{array}{c}0-30 \\
\text { Días }\end{array}$ & $\begin{array}{c}31-60 \\
\text { Días }\end{array}$ & $\begin{array}{c}61-90 \\
\text { Días }\end{array}$ & $\begin{array}{c}91-180 \\
\text { Días }\end{array}$ & $\begin{array}{c}181-360 \\
\text { Días }\end{array}$ & $\begin{array}{c}\text { Más de } 360 \\
\text { Días }\end{array}$ \\
\hline $\begin{array}{l}\text { Forwards, Swaps y } \\
\text { Opciones }\end{array}$ & $2.50 \%$ & $4.00 \%$ & $5.25 \%$ & $6.75 \%$ & $9.50 \%$ & $12.25 \%$ \\
Compradas & & & & & & \\
\hline
\end{tabular}

Fuente: Superintendencia de Banca, Seguros y AFP, SBS. (2018)

El Banco Interamericano de Finanzas es una de las entidades bancarias y que se encuentra habilitado para otorgar derivados financieros de monedas, así como otros productos de la mesa de dinero. Cuenta con una participación promedio de $6.2 \%$ al cierre del 2017 y es importante dado que, si bien el sistema financiero se encuentra actualmente conformado por cerca de 15 entidades bancarias, son pocas las que manejan el mercado de forwards como se demostró anteriormente.

Para las empresas que cierran derivados, el forward de monedas puede tener al vencimiento, ganancias o pérdidas, en un ejemplo sencillo, supongamos una empresa que va a tener que pagar un flujo en dólares que proviene de una deuda financiera con una 
institución bancaria del exterior y pacta un tipo de cambio forward venta por US $\$ 1$, 000,000.00 a 3.10 soles por dólar a una fecha futura determinada. Podemos observar en el siguiente cuadro el beneficio económico que obtendría en diferentes escenarios dependiendo del tipo de cambio en el vencimiento de la operación.

Figura 6.3

Beneficio económico de un forward

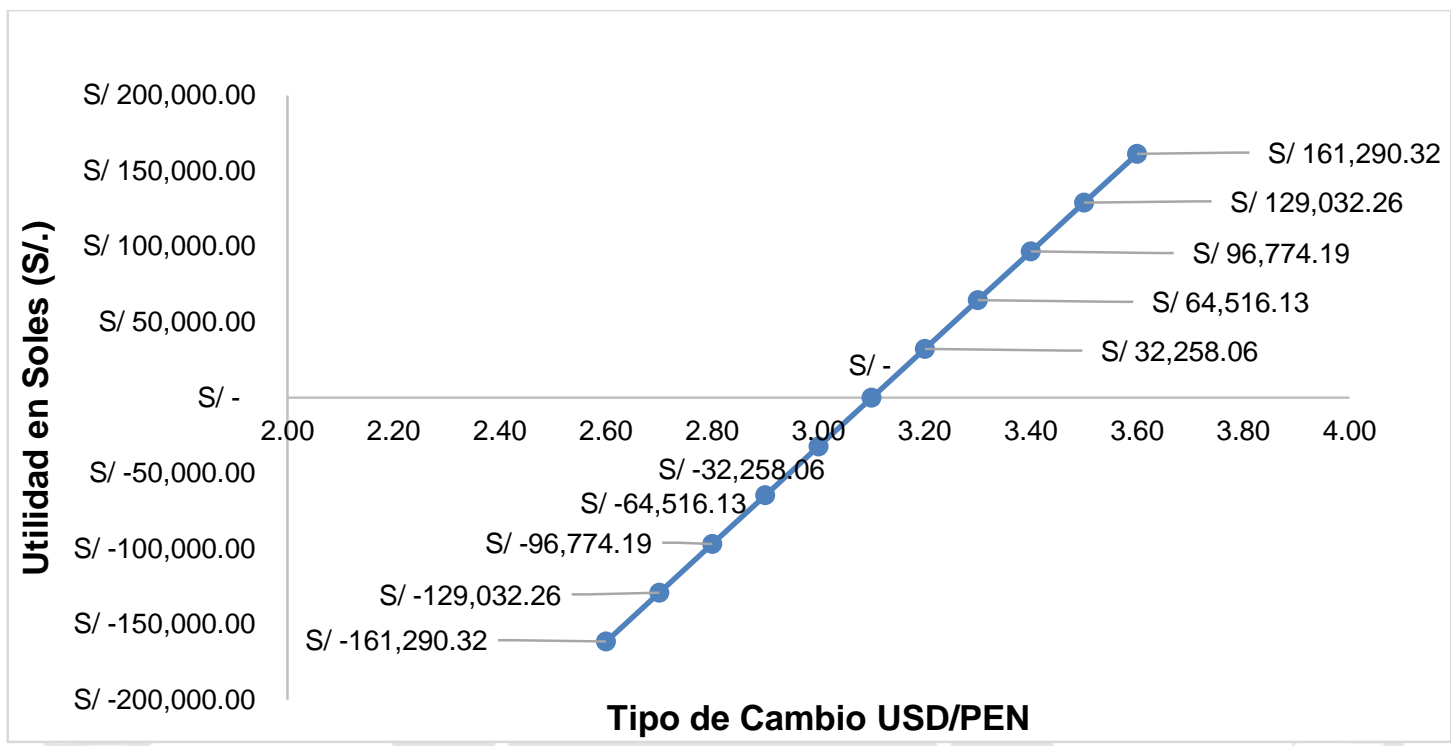

Fuente: Elaboración Propia (2018)

En el caso que la empresa no hubiera tomado la cobertura y el tipo de cambio hubiese subido al vencimiento, tendría una pérdida dado que para pagar la deuda del exterior necesitaría una mayor cantidad de soles. Del lado opuesto, si el tipo cambio hubiese bajado, estaría usando una mayor cantidad de moneda local para afrontar su deuda y se concluiría que no debería haber tomado la cobertura. Pero lo fundamental es buscar eliminar la volatilidad cambiaria, dado que esa no es la tarea principal de las empresas, por lo que si bien las instituciones recomiendan impulsar este mercado y enfatizar a las empresas que deben reducir volatilidad cambiaria fijando el tipo de cambio para flujos futuros y simplificar la planificación financiera, es aún más importante conocer como calcular adecuadamente el derivado financiero para tomar una gestión eficiente que no se vea afectada por los ganancias de las instituciones financieras y también tomar en cuenta los factores que afectan el tipo de cambio nominal y las expectativas futuras de los agentes económicos que realizan proyecciones sobre esta variable y que si bien pueden no ser exactos, brindan indicadores con fundamento del 
posible comportamiento del tipo de cambio. Esto será primordial para analizar y llegar a la toma de decisiones adecuadas para no verte expuesto a perdidas por tipo de cambio. Se precisa que el tipo de cambio nominal es el precio de una moneda versus otra y el precio se encuentra en base a la oferta y demanda del mismo. Es necesario resumir los determinantes del tipo de cambio para que, a través de las proyecciones y análisis fundamentales, se proceda a tomar una decisión para cerrar los flujos de cajas futuros con diferencia de cambio.

En el mundo existen diversos regímenes de tipo de cambio y cada país es libre de elegir el régimen que considere óptimo, como en el caso peruano, por ejemplo, nos encontramos en un régimen cambiario flotante con intervención, que significa que el tipo de cambio es determinado por la oferta y demanda del mercado y el Banco central interviene para evitar las fluctuaciones bruscas.

Existen una infinidad de factores que influyen en el tipo de cambio spot; entre los factores que con frecuencia alteran las expectativas de los participantes del mercado, se encuentra la política monetaria, los eventos externos que influyan en la toma de decisión para posición de activos en una determinada moneda y el comportamiento de la actividad económica (Arena y Tuesta, 1999, p. 3).

En principio, la política monetaria está relacionada directamente pues la autoridad monetaria puede inyectar o esterilizar una determinada moneda y afectar el tipo de cambio; la intervención se hace a través de la tasa de encaje de moneda nacional y/o extranjera, así como con la tasa de interés de referencia, las intervenciones de compra y venta en mercado spot, con swaps cambiarios, entre otros. Las expectativas de estos instrumentos, principalmente de la tasa de interés y la tasa de encaje, ya sean del Banco central peruano o del país extranjero también son tomadas en cuenta en las proyecciones de tipo de cambio dado que los agentes económicos van anticipando los efectos posibles ante variaciones futuras. En segundo lugar, se encuentran una diversidad de eventos externos que pueden ser, el riesgo político y mediático en donde un temor por cambios gubernamentales y en general movimientos de cargos en las autoridades locales se reflejan en incertidumbre y depreciación de la moneda nacional pues siempre existe un riesgo que estos cambios modifiquen el trayecto de la economía, cambios en la institucionalidad y/o leyes que vayan en desmedro de los tenedores de activos. Otro elemento fundamental, son los vencimientos de los derivados financieros, como lo revisado en este caso de estudio, los forwards de monedas al vencimiento se convierten en operaciones spot y afectan el mercado en caso no sean renovados. Igualmente están 
los vencimientos de los cupones y valores nominales de los instrumentos de renta fija, como por ejemplo cupones de bonos de tenedores extranjeros, quienes compran dólares para realizar sus ganancias y se llevan los dólares a su país de origen. Este último punto unido de expectativas negativas de la economía peruana, puede generar una fuerte presión al alza del tipo de cambio, pues una salida de capitales en grandes cantidades, genera escasez de dólares. Principalmente, este último dato se refleja posteriormente en la cuenta corriente de la balanza de pagos, conocida como renta de factores. Como menciona Solano (2006), la renta de factores está compuesta por la renta de inversión, la renta de los intereses, como las utilidades y dividendos que se pagan a los no residentes y además los salarios suscritos con no residentes (p.11)

Otro elemento importante, es la expectativa por la evolución relativa en términos productivos de una economía, considerando también el manejo de sus cuentas fiscales y foráneas; aclarando que no es el mismo manejo sino las noticias relacionadas a futuro (Arena y Tuesta, 1999, p. 3). Al mismo tiempo, se considera en el análisis, el resultado de la balanza comercial en cuenta corriente debido a que muestra el nivel de exportaciones e importaciones de bienes y servicios y es posible determinar por ejemplo si tenemos un país con una balanza comercial positiva que ha tenido una mayor cantidad de ingreso de dólares y por ende se estima que la oferta de divisas foráneas será mayor y el tipo de cambio tendrá una presión a la baja por la cantidad que aumentó de circulante de dólares.

Jeff madura (2009), lista una serie de variables que modifican la curva de oferta y demanda de una determinada moneda y que influyen en el tipo de cambio de manera directa. Estas son la variación en los diferenciales de inflación, en las tasas de interés, en los niveles de ingreso, así como en las expectativas sobre el futuro del tipo de cambio y por último sobre los controles gubernamentales como las barreras cambiarias, barreras al comercio exterior, intervención mediante compra o venta en el mercado spot o influencia en variables de la política monetaria; considerando estos factores de manera relativa entre un país con respecto a otro (pp. 87-94).

Estos son los principales determinantes que considero deberían ser tomados en cuenta para tomar decisiones, sin embargo, existe una gran cantidad de elementos adicionales que intervienen tanto en el corto como en el largo plazo y la predicción no llegará a ser exacta, pero lo que se busca es tener un número de indicadores que permita decidir cerrar los flujos excedentes o faltantes a futuro para reducir el impacto que puede tener la volatilidad del cambio de soles en términos de dólares. 
Pero como indica Madura (2009) se debe tomar en cuenta también que en cada economía existe un impacto de liquidez y dado que cada economía es distinta, así también será el proceso de ajuste del tipo de cambio ante un evento de volatilidad (p.86).

Se observará la serie de tiempo del tipo de cambio, para analizar los movimientos que ha tenido en los últimos 03 años, analizando los impactos en los balances de un conjunto de empresas supervisadas por la Superintendencia de Mercado de Valores para los periodos del 2015 al 2018 mediante la cuenta contable diferencia de cambio neto y realizar una comparación con la utilidad operativa de la empresa para apreciar el porcentaje de afecto sobre los resultados contables. Cabe precisar, que estas pérdidas o ganancias son contables hasta antes que se realice el pago puesto que la variable importante, tipo de cambio, puede tener una subida o bajada drástica sin embargo la empresa solo tendría un efecto relativo pues no tiene la necesidad de cambiar su flujo hasta el momento de honrar su deuda y es en la fecha en la cual se realiza la ganancia o pérdida. Debido a que los estados financieros se publican trimestralmente, se calcula este resultado a dicha fecha sin necesidad de implicar que se esté teniendo el efecto monetario real.

Se puede observar en el siguiente grafico la tendencia que ha tenido el tipo de cambio, en un rango de 3.0965 y 3.4140 entre los periodos de inicios del 2015 y al cierre del 2018. Como podemos observar el mismo subió en solo el 2015 ligeramente un nivel mayor a $10 \%$, que definitivamente impacto de manera negativa a aquellas empresas sin coberturas que tenían obligaciones en moneda extranjera mayores a sus acreencias. De la misma forma en el 2017 tuvo una reducción mayor al 5.4\% desfavorable para las empresas exportadores o excedentarias en dólares. 
Figura 6.4

Tipo de cambio USDPEN, 2015-2018

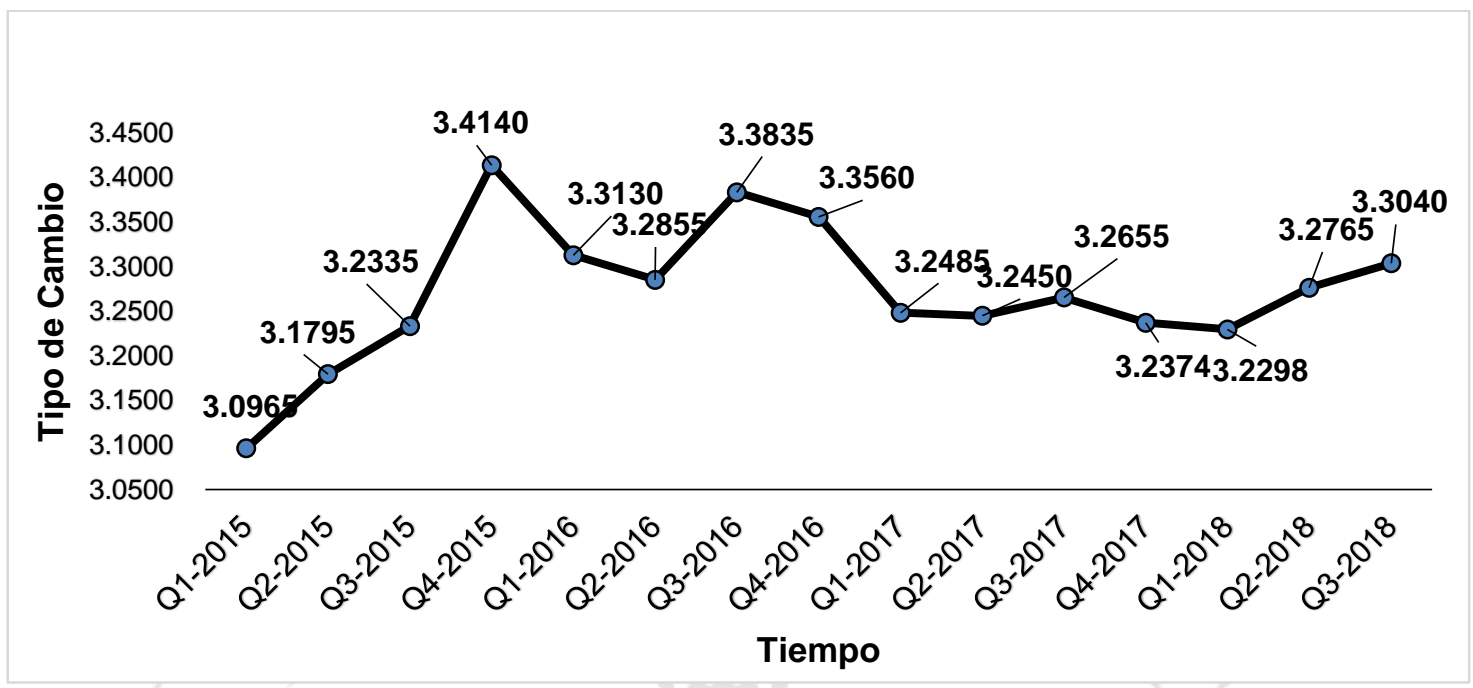

Fuente: Bloomberg. (2015-2018)

Se analizó la información de 53 empresas listadas en la Bolsa de Valores de Lima para observar cuanto representa de su ganancia operativa del negocio la pérdida o ganancia por tipo de cambio, mediante el ratio de la cuenta contable: pérdida de cambio neto sobre la utilidad operativa, por cada trimestre. Esta cuenta contable ha representado en el periodo del 2015 al 2018 en promedio general, un valor cercano al 30\%, con ratios desde el $2 \%$ hasta $200 \%$; además en total de todo el periodo analizado, el $70 \%$ de compañías tuvieron un perdida por la variación del tipo de cambio, resaltando el grado de importancia de controlar las volatilidades cambiarias y precisando que nos encontramos en el escenario que estas empresas tienen un nivel de control de riesgos y equipos encargados con mayor desarrollo a diferencia de la mayoría de empresas peruanas. Específicamente se revisaron los balances de empresas mineras las cuales manejan independientemente una estructura de activos y pasivos en moneda extranjera. 
Tabla 6.2

Ratio diferencia de tipo de cambio / utilidad operativa

\begin{tabular}{|c|c|c|c|c|c|c|c|c|c|c|c|c|c|}
\hline $\begin{array}{l}\text { UTILIDAD OPERATIVA } \\
\text { POR PERIODO }\end{array}$ & $\mathrm{I} 2015$ & II 2015 & III 2015 & IV 2015 & I2016 & II 2016 & III 2016 & IV 2016 & I2017 & II2017 & III 2017 & IV 2017 & I 2018 \\
\hline COMPAÑA MINERA 1 & $(5,954,00)$ & $(5,029.00)$ & $(6,411.00)$ & $(3,129.00)$ & $(3,960.00)$ & $1,204.00$ & $6,658.00$ & $33,201.00$ & $15,675,00$ & $12,735.00$ & $29,950.00$ & $64,552.00$ & $32,255.00$ \\
\hline COMPANIA MINERA 2 & $(1,727,00)$ & $1,263.00$ & $(10,577.00)$ & $1,200.00$ & $8,527.00$ & $11,541.00$ & $20,691.00$ & $20,559,00$ & $20,632.00$ & $29,324,00$ & $21,001.00$ & $4,611.00$ & $31,316,00$ \\
\hline COMPANIA MINERA 3 & $27,431.00$ & $25,552,00$ & $43,259.00$ & $43,520.00$ & $67,351.00$ & $71,741.00$ & $72,444,00$ & $51,979.00$ & $60,562.00$ & $76,026.00$ & $84,576.00$ & $77,487.00$ & $84,022.00$ \\
\hline COMPANIA MINERA 4 & $(2,058.00)$ & $(0,176.00)$ & $(8,809,00)$ & $(18,712.00)$ & $12,503.00$ & $37,838.00$ & $30,16,00$ & $9,169,00$ & $6,823: 00$ & $8,335.00$ & $27,136.00$ & $23,000.00$ & $18,859.00$ \\
\hline $\begin{array}{l}\text { DIF.POR TIP0 DE } \\
\text { CAMBIO NETO }\end{array}$ & I2015 & $\mathbb{I} 2015$ & III 2015 & IV 2015 & I2016 & II2016 & III2016 & IV 2016 & I2017 & II2017 & III 2017 & IV 2017 & I2018 \\
\hline COMPAÑA MINERA 1 & $2,228.00$ & $1,056.00$ & 670.00 & $1,922.00$ & $(1,110.00)$ & $(830.00)$ & $2,041.00$ & $(1,255.00)$ & $(3,980.00)$ & 144.00 & 346.00 & $(1,520.00)$ & $(901.00)$ \\
\hline COMPAÑA MINERA 2 & $(2,379.00)$ & $(1,916.00)$ & $(992.00)$ & $(4,568.00)$ & 1,71200 & 694.00 & $(2,247.00)$ & 373.00 & $1,451.00$ & $(249.00)$ & $(279.00)$ & $(61200)$ & $(157.00)$ \\
\hline COMPAÑIA MINERA 3 & $(5,275,00)$ & $(4,177,00)$ & $(2,293,00)$ & $(3,835.00)$ & $2,707.00$ & 494.00 & $(4,139,00)$ & $1,195.00$ & $3,578.00$ & $(372.00)$ & $(476.00)$ & 907.00 & 688.00 \\
\hline COMPANIA MINERA 4 & 140.00 & $1,561.00$ & (981.00) & $(1,326.00)$ & $5,131.00$ & $(2,024,00)$ & $(1,741.00)$ & 439.00 & $1,156,000$ & $1,737.00$ & $(1,801.00)$ & 46.00 & 234.00 \\
\hline $\begin{array}{l}\text { RATIO (DFERENCIA POR } \\
\text { TIP0 DE CAMBIO/ } \\
\text { UTILIDAD OPERATIIA) }\end{array}$ & I2015 & II2015 & III 2015 & IV 2015 & I2016 & II2016 & III2016 & IV 2016 & I2017 & II2017 & III 2017 & IV 2017 & I2018 \\
\hline CONPANIA MINERAI & $40 \%$ & $38 \%$ & $10 \%$ & $61 \%$ & $30 \%$ & $69 \%$ & $31 \%$ & $4 \%$ & $25 \%$ & $1 \%$ & $1 \%$ & $2 \%$ & $3 \%$ \\
\hline COMPAÑA MINERA 2 & $129 \%$ & $151 \%$ & $9 \%$ & $381 \%$ & $20 \%$ & $6 \%$ & $11 \%$ & $2 \%$ & $7 \%$ & $1 \%$ & $1 \%$ & $1 \%$ & $1 \%$ \\
\hline COMPAÑA MINERA 3 & $19 \%$ & $16 \%$ & $5 \%$ & $9 \%$ & $4 \%$ & $1 \%$ & $6 \%$ & $2 \%$ & $6 \%$ & $0 \%$ & $1 \%$ & $1 \%$ & $1 \%$ \\
\hline OMPANIA MINERA 4 & $7 \%$ & $22 \%$ & $11 \%$ & $7 \%$ & $41 \%$ & $5 \%$ & $6 \%$ & $5 \%$ & $17 \%$ & $21 \%$ & $7 \%$ & $0 \%$ & $1 \%$ \\
\hline
\end{tabular}

Fuente: Banco Interamericano de Finanzas, BANBIF. (2015-2018).

Elaboración Propia

Durante el año 2015, año de depreciación de la moneda peruana, se evidenció empresas con activos en dólares superiores a sus pasivos, reflejándose en efectos positivos durante este año, manejando un ratio de activos sobre pasivos entre 2 y 3 veces sin cobertura por lo que entrando en los periodos de apreciación de la moneda local, afrontaron también pérdidas lo que refleja una exposición a la variación sin límite, cabe resaltar que las perdidas y/o ganancias llegaron a representar entre el $4 \%$ y el $60 \%$ de sus resultados operativos en diversos trimestres. Por otro lado, también se halló que una empresa expresamente indica que la gerencia reconoce la existencia de un riesgo cambiario, subrayando que no se tomarán coberturas; resulta interesa ver que manejaban niveles de pasivos elevados con un ratio de 2.5 veces por encima de sus activos y al afrontar la perdida en el año 2015 se observó un incremento en sus cuentas corrientes, cuentas por cobrar comerciales y cuentas por cobrar a empresas relacionadas de manera gradual para reducir diferencias en el balance neto, llegando a revertir el ratio en el segundo trimestre del 2017, sumando a lo anterior las amortizaciones de las cuotas de sus 
préstamos en dólares. Por último, se precisa que la empresa con mayores niveles de pérdidas por tipo de cambio, manejaba un promedio de 6 veces sus obligaciones sobre acreencias, lo que generó una mayor exposición a la volatilidad y sin evidencias a lo largo del periodo de estudio de tomar coberturas o reducir la exposición.

Para profundizar el análisis sobre los derivados financieros de monedas y revisar si estos ayudan a mitigar la volatilidad cambiaria, se analizaron dos empresas, de diferente sector, que hayan tomado coberturas con el Banco Interamericano de Finanzas. El banco en mención, opera con empresas grandes y corporativas actualmente, que se encuentran en diversos sectores, dentro de los cuales están por ejemplo los sectores de telecomunicaciones, agroindustriales, financiero, consumo masivo, pesqueras y mineras principalmente pero también opera con bancos locales y del exterior por lo que se ha tomado a dos empresas para observar el manejo individual de cada una. Además, cabe hacer la precisión, que con el banco los clientes han realizado coberturas contra el dólar y el euro, sin embargo en la economía peruana existe una gran cantidad de operaciones hacia el continente Europeo y Asiático en monedas como francos suizos, libras, yenes, entre otras por lo que este estudio servirá para que las empresas con exposición en estas monedas, que no hayan explorado en este mercado de derivados, evalúen escenarios de volatilidad y tamaño de deuda o acreencias para ver si amerita tomar coberturas de riesgo mediante forwards de divisas.

La primera empresa, se encuentra en el rubro de la minería, dedicada al procesamiento y producción de concentrados de zinc, cobre, plomo y plata. Esta empresa proyecta su flujo de caja de 12 meses y al observar que tiene cuentas por cobrar a futuro proveniente de la venta de los minerales mayores a sus obligaciones financieras y no financieras y en el momento de cierre con expectativas, de entidades financieras, a la baja del tipo de cambio, principalmente por los resultados positivos de la balanza comercial y el aumento de precios de los minerales lo que se traduce en una oferta mayor de dólares; ha procedido a vender sus cobranzas adicionales proyectadas en plazos de 30, 45, 60, 90 y 120 días en promedio para anticipar el efecto cambiario.

La segunda, es una empresa es una petrolera dedicada al transporte, refinación, comercio y distribución de combustibles y productos derivados del petróleo, la cual maneja sus flujos en soles, pero gran parte de su deuda se encuentra en dólares por lo que son intensivos en el mercado derivado, sabiendo la responsabilidad que tienen de tomar coberturas para prevenir pérdidas importantes y lo hace en plazos de 45 a 180 días cuando 
el mercado se observa que el mercado se encuentra en sus niveles mínimos o por debajo de su proyección a inicios de año.

La contabilidad de los mismos es importante, según menciona Sánchez (2006), los forwards según la norma internacional contable número 39 (NIC 39), los derivados de cobertura pueden ser contabilizados a valor razonable, flujo de efectivo y por una inversión neta en un negocio en el extranjero; estos usualmente se realizan bajo la primera modalidad (p.1). Esto quiere decir que se utilizan las tasas y el precio spot de mercado y al cierre de cada mes calculan cada derivado por el plazo remanente de vida que tienen; en otras palabras, se calcula la diferencia entre el tipo de cambio forward por el monto cerrado inicialmente comparado con el valor presente del tipo de cambio forward de la fecha a calcular a tasa de interés de mercado en ese momento. Bernard (1992) en un estudio realizado a las entidades financieras de Dinamarca, resalta que la literatura contable es complicada y no hay un sistema óptimo que incorpore todos los efectos de valor de mercado y es importante considerar la complejidad en medir los precios de mercado pues estos serán los utilizados por las autoridades por lo que pueden ser vulnerables a manipulaciones (p.5). Se hace hincapié en que la evolución de los derivados debe ir junto a una igualdad contable para todas las compañías pues dado que no muchas empresas en la actualidad utilizan las coberturas como fue resaltado anteriormente, representa una complejidad elevada para los contadores y muchas veces es un factor desfavorable por el cual las empresas deciden no prevenir el efecto cambiario. 


\section{ANÁLISIS Y DISCUSION DE RESULTADOS}

Se realiza la precisión que todos los resultados se encuentran bajo el supuesto de que las empresas toman posición en derivados a precios eficientes de mercado para ver el impacto real, dado que en la actualidad la entidad financiera tiene una ganancia, diferente por cada cliente, al asumir ser contraparte de los mismos por lo que si se va a entrar a negociar este tipo de derivados debemos necesariamente saber calcular el tipo de cambio futuro o en el caso de contar con Bloomberg, observar los precios de compra y venta del mercado forward para buscar obtener precios cercanos.

En cuanto a las empresas analizadas; la primera empresa minera, tomó coberturas en mayo del 2018, cuando el tipo de cambio spot se cotizaba en 3.2800 y cerró 02 operaciones forward de la siguiente forma:

Tabla 7.1

Ejemplo I: Forward de empresa minera, 2018

\begin{tabular}{|c|c|c|c|c|c|c|c|}
\hline & $\begin{array}{l}\text { Tipo de Cambio } \\
\text { Spot }\end{array}$ & \begin{tabular}{|l|} 
Tipo de Cambio \\
Forward \\
Compra
\end{tabular} & Plazo (En días) & Monto & Mes & \begin{tabular}{|l} 
Tipo de \\
Cambio al \\
Vencimiento \\
\end{tabular} & Utilidad o Pérdida \\
\hline Operación 1 & 3.28 & 3.2923 & 28 & $\$ 300,000.00$ & Mayo & 3.2680 & $\$ 2,230.72$ \\
\hline Operación 2 & 3.278 & 3.2885 & 45 & $\$ 500,000.00$ & Mayo & 3.2750 & $\$ 2,061.07$ \\
\hline
\end{tabular}

Fuente: Banco Interamericano de Finanzas, BANBIF. (2018).

Elaboración Propia

De la misma forma, en Junio del 2018 continuó cerrando flujos a futuro con tipo de cambio spot en 3.2820 y 3.2800 , en esta oportunidad cerrando en plazos de 30, 45 y 105 días según se observa:

Tabla 7.2

Ejemplo II: Forward de empresa minera, 2018

\begin{tabular}{|l|r|r|r|r|l|r|r|}
\hline & $\begin{array}{l}\text { Tipo de Cambio } \\
\text { Spot }\end{array}$ & $\begin{array}{l}\text { Tipo de Cambio } \\
\text { Forward } \\
\text { Compra }\end{array}$ & Plazo (En días) & Monto & Mes & $\begin{array}{l}\text { Tipo de } \\
\text { Cambio al } \\
\text { Vencimiento }\end{array}$ & Utilidad o Pérdida \\
\hline Operación 1 & 3.282 & 3.2865 & 30 & $\$ 300,000.00$ & Junio & 3.2470 & $\$ 3,649.52$ \\
\hline Operación 2 & 3.282 & 3.2875 & 45 & $\$ 300,000.00$ & Junio & 3.2400 & $\$ 4,398.15$ \\
\hline Operación 3 & 3.28 & 3.2933 & 105 & $\$ 500,000.00$ & Junio & 3.2730 & $\$ 3,101.13$ \\
\hline
\end{tabular}

Fuente: Banco Interamericano de Finanzas, BANBIF. (2018).

Elaboración Propia 
Como se puede interpretar de los resultados, si bien en ambos casos obtuvo ganancias por el tipo de cambio al vencimiento versus el tipo de cambio forward pactado, lo importante es notar que los precios spot que tomaron durante el mes se encontraron entre los más altos de cada mes respectivamente, y esto debido a incertidumbre política local, uno de los factores que afectan el mercado cambiario.

Por otro lado, como se había mencionado en el caso de la petrolera, esta toma coberturas a inicios de año entre Enero y Marzo, buscando niveles favorables y por debajo del cierre del anterior año o cuando el mercado tiene expectativas negativas, para prevenir la depreciación del sol peruano.

Tabla 7.3

Ejemplo III: Forward de empresa petrolera, 2018

\begin{tabular}{|c|c|c|c|c|c|c|c|}
\hline & $\mid \begin{array}{l}\text { Tipo de Cambio } \\
\text { Spot }\end{array}$ & $\begin{array}{l}\text { Tipo de Cambio } \\
\text { Forward Venta }\end{array}$ & Plazo (En días) & Monto & Mes & \begin{tabular}{|l} 
Tipo de \\
Cambio al \\
Vencimiento
\end{tabular} & Utilidad o Pérdida \\
\hline Operación 1 & 3.2250 & 3.2299 & 62 & $\$ 20,977,781.00$ & Enero & 3.2540 & $\$ 155,367.09$ \\
\hline Operación 2 & 3.2160 & 3.2206 & 43 & $\$ 21,635,069.44$ & Enero & 3.2510 & $\$ 202,308.86$ \\
\hline Operación 3 & 3.2125 & 3.2169 & 47 & $\$ 22,898,746.50$ & Enero & 3.2600 & $\$ 302,741.10$ \\
\hline Operación 4 & 3.2134 & 3.2184 & 56 & $\$ 22,748,569.74$ & Enero & 3.2510 & $\$ 228,115.46$ \\
\hline Operación 5 & 3.2550 & 3.2659 & 113 & $\$ 24,447,647.64$ & Marzo & 3.2870 & $\$ 156,935.01$ \\
\hline Operación 6 & 3.2555 & 3.2644 & 96 & $\$ 26,126,890.04$ & Marzo & 3.2700 & $\$ 44,743.30$ \\
\hline Operación 7 & 3.2505 & 3.2668 & 175 & $\$ 24,405,339.11$ & Marzo & 3.3300 & $\$ 463,188.42$ \\
\hline Operación 8 & 3.2390 & 3.2499 & 124 & $\$ 15,961,094.38$ & Marzo & 3.2700 & $\$ 98,109.48$ \\
\hline Operación 9 & 3.2390 & 3.2572 & 194 & $\$ 17,265,401.01$ & Marzo & 3.3130 & $\$ 290,796.67$ \\
\hline Operación 10 & 3.2410 & 3.2549 & 169 & $\$ 25,420,016.25$ & Marzo & 3.3230 & $\$ 520,945.86$ \\
\hline
\end{tabular}

En este caso, la empresa también tuvo resultados favorables que le hubieran generado diferencias importantes en su estado de resultados en caso de no haber tomado sus coberturas. En el transcurso del año continúa cubriendo flujos cuando el precio spot está dentro de su precio objetivo recalcando que cierra sus operaciones con finalidad de cobertura.

Las empresas revisadas tomaron una gestión eficiente de sus flujos. En el primer caso, el nivel del mercado se encontraba por encima de su precio objetivo por lo cual decidió prevenir un retroceso del sol peruano y en caso el mercado hubiera continuado al alza, no debería ser una variable importante pues lo principal es evitar pérdidas que influyan en el resultado general de las empresas. Por otro lado, en el caso de la empresa petrolera, esta también tuvo un resultado positivo, sin embargo, como se ha tratado de recalcar en este estudio, lo primordial no es el resultado final del derivado siempre y 
cuando este sea de cobertura sino de considerar al tipo de cambio con una variable importante en la toma de decisiones del negocio y buscar precios eficientes para reducir la exposición cambiaria. Esto es fundamental tomar en cuenta pues existen empresas que han optado por no tomar derivados financieros por experiencias pasadas, en donde el derivado arrojó una pérdida, sin embargo, sus flujos tenían una exposición muy baja a la variación, pero se pensaba que lo mejor hubiera sido no tomar la cobertura.

En conclusión, se analizó la información obtenida y recopilada en el punto 6 y con la metodología planteada se pudo ver que los resultados obtenidos demuestran la importancia de considerar las expectativas del tipo de cambio y la posibilidad de tomar el derivado financiero, forward de monedas, como una salida para desvincularse de la posible pérdida por descalce de balance. Actualmente se muestra que no hay muchas entidades financieras que actúan como contrapartes, principalmente manejado por 5 bancos y estamos en un mercado con una posición bruta de forwards, es decir la suma de compras y ventas, de US\$36 mil millones de dólares que comparado al mercado global es una cifra inferior, mostrando un mercado poco líquido y muy probable con poca competencia de precios. Más aun, todavía continua un gran número de empresas que no están dispuestas a tomar coberturas por múltiples razones como falta de capacitación, experiencias negativas pasadas y poca consideración de los impactos negativos que pueden tener las variaciones del mercado spot.

Este análisis tiene una implicancia económica y demuestra que muchas empresas pueden mitigar el riesgo por lo que es algo positivo y se busca que el sistema bancario sea más flexible y pueda pedir garantías para otorgar este tipo de líneas a los clientes. Se mostró que la mayoría de empresas se ven afectadas por esta variable y en muchos casos ésta representa gran parte de sus ingresos producto del propio negocio por lo que se recomienda evaluar los escenarios posibles de pérdidas o ganancias dado el tamaño de la firma y su nivel de exposición y prevenirla mediante los derivados financieros forwards de monedas, o al menos reducir la incertidumbre cambiaria. Los accionistas se han visto expuestos durante años al riesgo de cambio y muchas veces los resultados favorables del propio negocio se ven mermados por variaciones que eran controlables de manera interna.

Por último, resaltar que tomar coberturas de manera eficiente, reduce la volatilidad de los márgenes finales de la empresa y además permite fijar un tipo de cambio para los flujos de caja futuros lo que genera que las empresas puedan realizar proyecciones sensatas y necesarias para poder dedicar su potencial en el objetivo 
principal de cada negocio y tener un dato preciso para realizar una estructura de ingresos y costos y por ende tener el control aproximado de los márgenes de la industria. 


\section{RECOMENDACIONES}

A continuación, detallaré las recomendaciones:

Con base a lo demostrado en el análisis, se busca culturizar y diluir el efecto de hoja de balance en la mayoría de empresas que se encuentran expuestas a la variación del tipo de cambio. Resulta indispensable para los diferentes participantes encargados de las compañías, quienes deberían tener conocimiento y estar abiertos a cotizar y estar capacitados para tomar en cuenta el derivado financiero forward de monedas como una alternativa en el caso que se proyecte el flujo de caja de un periodo determinado con un descalce cambiario presente y en un mercado interbancario favorable o con expectativas variadas que finalmente se dé la posibilidad de reducir el riesgo.

Los accionistas se han visto expuestos durante años al riesgo de cambio y muchas veces los resultados favorables del propio negocio se ven mermados por variaciones no son controlables de manera interna. Los inversionistas, hoy en día, toman en cuenta la capacidad del manejo de riesgos y por otro lado los reguladores se deben encontrar en la capacidad de mostrar reglas claras tanto en la contabilidad como en las normas de uso de los derivados para generar una alternativa confiable de uso y de esta forma represente una forma de mitigar un riesgo y no generar uno adicional, puesto que existen empresas que no desean tomar coberturas por experiencias anteriores, una mala asignación de precios dados los pocos competidores o mala asesoría para la toma de decisiones. Se deben generar charlas didácticas y capacitaciones al público en general, donde se culturice y enseñe desde los conceptos básicos hasta modelos de manejo eficiente para que las empresas se involucren en el mercado de derivados. 


\section{REFERENCIAS}

Arena M. y Tuesta, P. (1999). El objetivo de la intervención del banco central: ¿el nivel del tipo de cambio, la reducción de la volatilidad cambiaria o ambos?: Un análisis de la experiencia peruana 1991-1998. Recuperado del sitio de Internet del Banco Central de Reserva del Perú: http://suscripciones.bcrp.gob.pe/docs/Publicaciones/Revista-EstudiosEconomicos/05/Estudios-Economicos-5-3.pdf

Banco Central de Reserva del Perú. (2006). El Efecto hoja de balance. Recuperado del sitio de Internet del Banco Central de Reserva del Perú: http://www.bcrp.gob.pe/docs/Publicaciones/ReporteInflacion/2006/setiembre/ri-setiembre-2006-recuadro-2.pdf

Banco Central de Reserva del Perú. (2007). La cobertura cambiaria: los forwards de divisas. Recuperado del sitio de Internet del Banco Central de Reserva del Perú: http://www.bcrp.gob.pe/docs/Publicaciones/Informes-Especiales/CoberturaCambiaria-Forwards-Divisas.pdf

Banco Interamericano de Finanzas, BANBIF. (2018). Forward [Base de datos].

BBVA, Banco Continental del Perú. (2007). Mercado de Derivados en el Perú. Recuperado del sitio de Internet del Banco Central de Reserva del Perú: http://www.bcrp.gob.pe/docs/Publicaciones/Informes-Especiales/CoberturaCambiaria-BBVA-3.pdf

Bernard, V. (1992). Mark-to-Market accounting for U.S. Banks and thrifts: lessons from the Danish experience ( $N{ }^{\circ} 48109$-1234). Recuperado del sitio de Internet de la Universidad de Michigan:

https://deepblue.lib.umich.edu/bitstream/handle/2027.42/35401/b1657781.0001. 001.pdf? sequence $=2 \&$ is Allowed $=\mathrm{y}$

Bloomberg. (2018). Tipo de Cambio USD/PEN [Base de datos]. Recuperado de https://www.bloomberg.com/

Contreras, A., Quispe, Z., Regalado, F. y Martínez, M. (2017). Dolarización real en el Perú. Recuperado del sitio de Internet del Banco Central de Reserva del Perú: http://www.bcrp.gob.pe/docs/Publicaciones/Revista-EstudiosEconomicos/33/ree-33-contreras-quispe-regalado-martinez.pdf

Chang, G. (2013). Riesgo Cambiario en las empresas. Recuperado del sitio de Internet del Banco Central de Reserva del Perú: http://www.bcrp.gob.pe/docs/Publicaciones/Revista-Moneda/moneda$\underline{156 / \text { moneda-156-03.pdf }}$ 
Fisanotti, L (2014). Antecedentes Históricos de los mercados de Futuros y Opciones: Cobertura y Especulación. Invenio, 17(33), 16. Recuperado de http://www.redalyc.org/pdf/877/87732404002.pdf

Hull, J. (2009). Introducción a los mercados de futuros y opciones (6. ${ }^{\mathrm{a}}$ ed.). México D. F: Pearson Educación.

Ley N. ${ }^{\circ} 14354-2009$, Reglamento para el requerimiento de patrimonio efectivo por riesgo de crédito. (30 de octubre del 2009). Recuperado del sitio de internet de la Superintendencia de Banca, Seguros y Administradora de Fondo de Pensiones: https://intranet2.sbs.gob.pe/intranet/INT_CN/DV_INT_CN/976/v5.0/Adjuntos/1 4354-2009.r.pdf

Madura, J. (2009). Administración Financiera Internacional. (9. a ed.). México D. F Cengage.

Solano, J. (2006). La Balanza de Pagos (N 10 ISSN 1794-029X). Recupera del sitio de Internet de la Universidad ICESI:

https://www.icesi.edu.co/departamentos/economia/publicaciones/docs/Apecon1 $\underline{0 . p d f}$

Sánchez, L. (2009). Contabilidad de cobertura usando el Forward. Actualidad Empresarial, 6(174), 1-3. http://www.aempresarial.com/web/revitem/9_8968_49062.pdf

Superintendencia de Banca, Seguros y AFP, SBS. (2018). Operaciones Forward en Moneda Extranjera [Base de datos]. Recuperado de http://www.sbs.gob.pe/app/stats_net/stats/EstadisticaBoletinEstadistico.aspx?p= $\underline{1 \#}$ 


\section{BIBLIOGRAFÍA}

Jimeno, M. Knop, R. Librero, G. y García, M. (2013). Instrumentos derivados para la empresa (2. ${ }^{\mathrm{a}}$ ed.). Madrid.: Delta.

Isidro, N, López, Z, y Martínez, T. (2012). Mercados financieros y derivados. Madrid.: ESIC Editorial.

Rona, J. (2007). Guía práctica de los instrumentos financieros derivados. Recuperado de https://ebookcentral-proquest-com

Ross, J. (2012). Finanzas Corporativas (9. a ed.). México D. F.: McGraw-Hill Companies, Inc. 


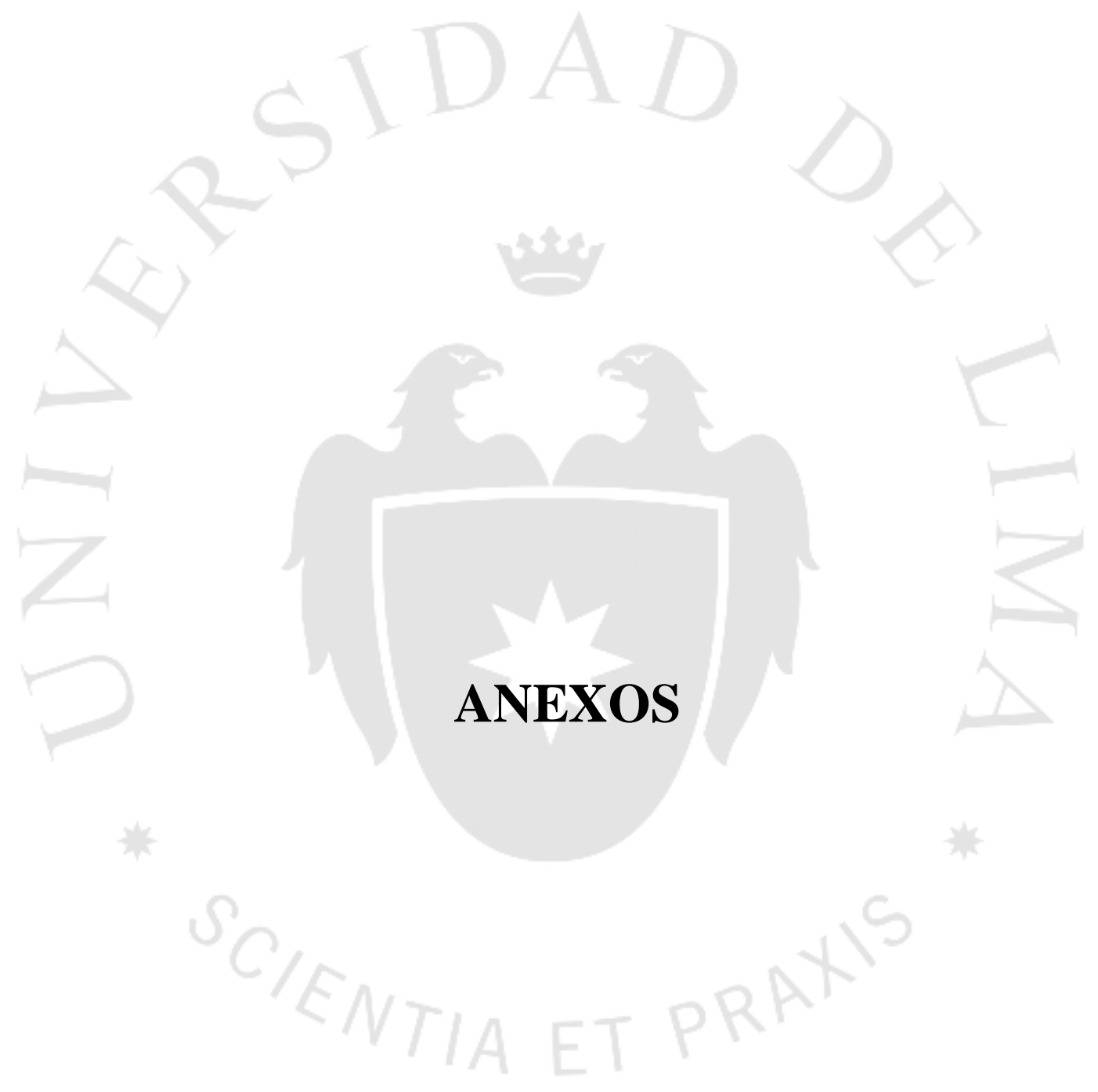




\section{Anexo 1: Exposición Bruta de Forwards, 2001-2017}

\begin{tabular}{|l|r|r|r|r|}
\hline & Diciembre 2001 & Diciembre 2002 & Diciembre 2003 & Diciembre 2004 \\
\hline B. Continental & $374,355.08$ & $575,166.36$ & $377,022.17$ & $986,017.46$ \\
\hline B. de Crédito del Perú & $548,007.47$ & $1,216,553.05$ & $985,653.27$ & $1,503,653.35$ \\
\hline B. Pichincha* & $15,642.58$ & $19,327.00$ & - & $54,871.21$ \\
\hline $\begin{array}{l}\text { B. Interamericano de } \\
\text { Finanzas }\end{array}$ & - & & & \\
\hline Scotiabank Perú & & & $20,764.97$ & $96,907.58$ \\
\hline Citibank & $301,425.77$ & $383,327.28$ & $189,073.09$ & $445,539.89$ \\
\hline Interbank & $123,006.19$ & $121,133.76$ & $285,798.38$ & $371,705.59$ \\
\hline B. GNB & - & & - & - \\
\hline B. Santander Perú & - & - & - & - \\
\hline Deutsche Bank Perú & - & - & - & - \\
\hline Otros ** & - & - & - & - \\
\hline TOTAL BANCA MÚLTIPLE & $2,330,046.00$ & $2,537,379.00$ & $1,825,953.00$ & \multicolumn{2}{|c|}{$1,977,605.00$} \\
\hline
\end{tabular}

\begin{tabular}{|c|c|c|c|c|}
\hline 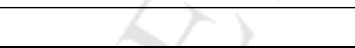 & Diciembre 2005 & Diciembre 2006 & Diciembre 2007 & Diciembre 2008 \\
\hline B. Continental & $2,444,605.97$ & $2,721,711.04$ & $8,213,407.49$ & $13,498,577.00$ \\
\hline B. de Crédito del Perú & $4,051,112.75$ & $3,721,910.43$ & $6,641,856.54$ & $7,761,379.07$ \\
\hline B. Pichincha* & $48,065.75$ & $36,639.21$ & $118,867.71$ & $6,364.13$ \\
\hline $\begin{array}{l}\text { B. Interamericano de } \\
\text { Finanzas }\end{array}$ & $72,767.45$ & $28,459.34$ & $3,774.50$ & $16,125.04$ \\
\hline Scotiabank Perú & $1,311,288.03$ & $2,988,757.99$ & $4,531,035.94$ & $6,228,718.69$ \\
\hline Citibank & $630,209.93$ & $987,438.08$ & $1,813,198.21$ & $4,806,552.62$ \\
\hline Interbank & $301,133.27$ & $1,370,204.43$ & $1,940,575.17$ & $2,195,706.30$ \\
\hline B. GNB & - & - & - & $104,959.52$ \\
\hline B. Santander Perú & - & - & - & $601,835.01$ \\
\hline Deutsche Bank Perú & - & - & - & $673,001.82$ \\
\hline Otros $* *$ & 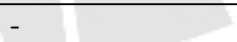 & - & - & - \\
\hline TOTAL BANCA MÚLTIPLE & $8,859,183.14$ & $11,855,120.52$ & $23,262,715.56$ & $35,893,219.19$ \\
\hline
\end{tabular}

\begin{tabular}{|l|r|r|r|r|r|}
\hline & \multicolumn{1}{|c|}{ Diciembre 2009 } & \multicolumn{1}{|c|}{ Diciembre 2010 } & \multicolumn{1}{c|}{ Diciembre 2011 } & \multicolumn{1}{c|}{ Diciembre 2012 } & \multicolumn{1}{c|}{ Diciembre 2013 } \\
\hline B. Continental & $9,025,763.51$ & $9,131,590.79$ & $5,721,589.40$ & $7,216,544.21$ & $11,889,467.28$ \\
\hline B. de Crédito del Perú & $7,683,952.08$ & $7,343,877.73$ & $9,321,085.40$ & $13,565,815.03$ & $13,529,475.72$ \\
\hline B. Pichincha* & $4,223.95$ & $40,730.50$ & $15,906.40$ & $139,719.61$ & $16,074.57$ \\
\hline $\begin{array}{l}\text { B. Interamericano de } \\
\text { Finanzas }\end{array}$ & & & & & \\
\hline Scotiabank Perú & & $47,195.24$ & $4,193.39$ & $17,416.50$ & $26,440.70$ \\
\hline Citibank & $4,435,663.98$ & $9,028,304.64$ & $6,808,861.55$ & $11,090,166.45$ & $17,691,206.72$ \\
\hline Interbank & $2,444,240.34$ & $4,690,312.75$ & $2,967,366.14$ & $7,901,805.63$ & $8,532,161.14$ \\
\hline B. GNB & $3,071,337.68$ & $5,048,139.18$ & $4,030,926.19$ & $5,035,503.54$ & $6,311,186.07$ \\
\hline B. Santander Perú & $511,560.72$ & $1,768,298.10$ & $1,711,685.11$ & $539,653.25$ & $5,643.11$ \\
\hline Deutsche Bank Perú & $704,657.18$ & $1,710,600.46$ & $1,197,832.80$ & $3,312,970.47$ & $1,619,333.02$ \\
\hline Otros ** & $1,782,503.22$ & $3,815,246.52$ & $2,573,212.25$ & $2,717,378.21$ & $4,303,627.83$ \\
\hline TOTAL BANCA MÚLTIPLE & $28,900.00$ & - & - & - & - \\
\hline
\end{tabular}

(continúa) 
(continuación)

\begin{tabular}{|l|r|r|r|r|}
\hline & \multicolumn{1}{|c|}{ Diciembre 2014 } & \multicolumn{1}{|c|}{ Diciembre 2015 } & \multicolumn{1}{c|}{ Diciembre 2016 } & \multicolumn{1}{c|}{ Diciembre 2017 } \\
\hline B. Continental & $17,449,564.38$ & $12,755,765.60$ & $9,567,860.34$ & $9,473,514.14$ \\
\hline B. de Crédito del Perú & $14,322,379.19$ & $8,829,706.08$ & $6,275,415.96$ & $9,361,231.39$ \\
\hline B. Pichincha* & $23,386.06$ & $25,582.50$ & $6,520.71$ & - \\
\hline $\begin{array}{l}\text { B. Interamericano de } \\
\text { Finanzas }\end{array}$ & $29,055.69$ & $155,236.32$ & $1,163,858.71$ & $2,250,429.86$ \\
\hline Scotiabank Perú & $16,548,259.86$ & $11,267,083.96$ & $4,950,383.25$ & $5,123,342.74$ \\
\hline Citibank & $7,848,180.97$ & $3,882,662.01$ & $1,469,353.66$ & $2,526,689.32$ \\
\hline Interbank & $9,134,404.69$ & $5,131,813.80$ & $3,961,082.65$ & $5,473,644.01$ \\
\hline B. GNB & $41,902.54$ & - & - & $68,131.01$ \\
\hline B. Santander Perú & $1,138,668.57$ & $336,854.74$ & $839,378.46$ & $1,476,927.58$ \\
\hline Deutsche Bank Perú & $5,085,201.65$ & $2,162,541.74$ & - & - \\
\hline Otros ** & - & & $23,492.00$ & $145,845.00$ \\
\hline TOTAL BANCA MÚLTIPLE & $71,621,003.61$ & $44,547,246.76$ & $28,257,345.72$ & $35,899,755.04$ \\
\hline
\end{tabular}

Fuente: Superintendencia de Banca, Seguros y AFP, SBS (2001-2017) 


\section{Anexo 2: Utilidad Operativa de empresas listadas en la SMV ,}

2015 - 2018

\begin{tabular}{|c|c|c|c|c|c|c|c|c|c|c|c|c|c|}
\hline Uílilidad Operativa(En miles de S/.) & 12015 & 112015 & III 2015 & IN2015 & 12016 & 112016 & |112016 & IN2016 & 12017 & |12017 & 1112017 & II 2017 & 12018 \\
\hline Empresa 1 & $298,689.00$ & $157,018.00$ & $141,706,00$ & $162,94 ., 00$ & $34,505,00$ & 148,6000 & $131,477.00$ & $99,770.00$ & $343,169.00$ & $140,999 ., 00$ & $120,369.00$ & $104,785.00$ & $227,771.00$ \\
\hline Empresa 2 & $5,465.00$ & $3,434.00$ & $3,091.00$ & $1,841.00$ & $4,469.00$ & $11,840.00$ & $10,701.00$ & $11,342,00$ & $11,541,00$ & $7,757.00$ & $8,293.00$ & $11,577.00$ & $10,764.00$ \\
\hline Empresa 3 & $54,29,00$ & $63,218.00$ & $94,978.00$ & $64,861.00$ & $97,36.00$ & $65,774.00$ & $52,655.00$ & $80,460.00$ & $68,755.00$ & $85,356.00$ & $86,970.00$ & $70,5860.00$ & $70,923.00$ \\
\hline Empresa 4 & $14,998.00$ & $(3,558.00)$ & $8,109.00$ & $38,211.00$ & $41,30.00$ & $42,657.00$ & 27,39900 & $17,43,00$ & 15,26200 & $18,83,00$ & $93,53,00$ & $52,534,00$ & $60,235.00$ \\
\hline Empresa 5 & $60,175.00$ & $38,233.00$ & $47,598.00$ & $46,653.00$ & $58,123.00$ & $41,101.00$ & $20,174,00$ & $38,300,00$ & $13,703.00$ & $19,052.00$ & $59,22,00$ & $70,5950.00$ & $70,109.00$ \\
\hline Empresa 6 & 3,30400 & $3,594.00$ & $1,529.00$ & $(1,475.00)$ & $3,037.00$ & $3,914,00$ & $1,033.00$ & $(1,257,00)$ & $3,694,00$ & $4,279.00$ & $1,826.00$ & $(1,041.00)$ & $3,107,00$ \\
\hline Empresa 7 & $67,499.00$ & $67,385.00$ & $65,242,00$ & $71,186.00$ & $45,271.00$ & $52,94,00$ & $58,023.00$ & $47,291.00$ & $40,251.00$ & $40,37,00$ & $57,922.00$ & $58,400.00$ & $41,686.00$ \\
\hline Empresa 8 & $21,826.00$ & $16,188.00$ & $13,438.00$ & $10,942,00$ & $5,557.00$ & $22,221,00$ & $12,303.00$ & $12,192,00$ & $5,87.00$ & $11,365.00$ & $5,015,00$ & $(8,893.00)$ & $26,839.00$ \\
\hline Empresa9 & 330.00 & 245.00 & 241.00 & $(3,42,00)$ & $(153.00)$ & $(1,318.00)$ & (975.00) & $(93,000)$ & 2.00 & $(136.00)$ & 90.00 & 90.00 & 8.00 \\
\hline Empresa 10 & $18,891.00$ & 21,760000 & $19,154.00$ & $15,316,00$ & $24,433.00$ & $26,623.00$ & $29,579.00$ & $27,006.00$ & $31,54,00$ & $28,237.00$ & $28,5090.00$ & $28,557.00$ & $23,732.00$ \\
\hline Empresa 11 & $4,004.00$ & $2,060.00$ & $(3,402,00)$ & $9,020,00$ & $4,518.00$ & $3,889.00$ & $9,303.00$ & $2,833.00$ & 164.00 & $4,965.00$ & $6,724,00$ & $(12,066,00)$ & $4,233.00$ \\
\hline Empresa 12 & $6,533.00$ & $1,097.00$ & $15,553.00$ & $21,322.00$ & $13,925.00$ & $4,162.00$ & $23,807.00$ & $20,098.00$ & $13,363.00$ & $5,210.00$ & $(14,662.00)$ & $4,799.00$ & $1,984,00$ \\
\hline Empresa 13 & $4,737.00$ & $3,534.00$ & $1,000.00$ & $5,362.20$ & $8,583.00$ & $1,328.00$ & $4,974,00$ & $4,856.00$ & $3,611.00$ & $2,966.00$ & 539.00 & $4,702,00$ & $5,193.00$ \\
\hline Empresa 14 & $6,214.00$ & $(1,863.00)$ & $4,009.00$ & $20,239.00$ & $5,377,00$ & $8,466.00$ & $23,506.00$ & $22,721.00$ & $7,24,00$ & $3,558.00$ & $7,871.00$ & $9,211.00$ & 913.00 \\
\hline Empresa 15 & $4,862.00$ & $7,500.00$ & $15,694,00$ & $11,446.00$ & $8,601.00$ & $13,786.00$ & $12,608.00$ & 984.00 & 8,91900 & $17,738.00$ & $14,028.00$ & $4,562.00$ & $5,293.00$ \\
\hline Empresa 16 & $18,339.00$ & $19,056.00$ & $33,613.00$ & $4,872,00$ & $18,607.00$ & $18,240.00$ & $4,666.00$ & $24,707.00$ & $12,850.00$ & $16,869.00$ & $34,27,00$ & $40,827.00$ & $34,046.00$ \\
\hline Empresa 17 & $5,517,00$ & $10,155.00$ & $8,643.00$ & $9,356.00$ & $6,974,00$ & $13,782.00$ & $10,755.00$ & $10,230.00$ & $7,374,00$ & $12,102.00$ & $14,262.00$ & $7,984,00$ & $8,199.00$ \\
\hline Empresa 18 & $9,8770.00$ & $49,156.00$ & $187,24,00$ & $(139,776.00)$ & $14,901.00$ & $12,451.00$ & $6,124,00$ & $7,731.00$ & $(21,436.00)$ & $41,473.00$ & $2,060.00$ & $42,271.00$ & $30,40,00$ \\
\hline Empresa 19 & $16,033.00$ & $16,999.00$ & $15,830.00$ & $18,900.00$ & $6,915.00$ & $16,155.00$ & $18,829.00$ & $14,76.00$ & $17,641.00$ & $17,64.00$ & 18314,00 & $22,549.00$ & $17,812.00$ \\
\hline Empresa 20 & 64.00 & 14,00 & 256.00 & 24,00 & 402,00 & 416.00 & 115.00 & 332.00 & $(6622.00)$ & 604.00 & 137.00 & $(885.00)$ & $(427,0)$ \\
\hline Empresa 21 & $15,24,00$ & $16,776.00$ & $17,79.00$ & 16,346000 & $15,866.00$ & $13,989.00$ & $11,927,00$ & $12,764,00$ & 14,91500 & $14,150.00$ & $16,35,00$ & $15,269.00$ & $16,75,00$ \\
\hline Empresa 22 & $4,997.00$ & $4,682.00$ & 4,835.00 & $3,701.00$ & $4,655.00$ & $4,552.00$ & $4,080.00$ & $3,400.00$ & $4,435.00$ & 2,145.00 & $3,53,00$ & $4,554.00$ & $3,609.00$ \\
\hline Empresa 23 & $4,041.00$ & $2,778.00$ & $5,035.00$ & 513.00 & $2,070.00$ & $5,147.00$ & 544.00 & $4,810.00$ & $1,003.00$ & $3,087.00$ & $3,790.00$ & $1,485.00$ & 5660.00 \\
\hline Empresa 24 & $19,255.00$ & $15,891.00$ & $16,27.00$ & $6,659.00$ & $12,562.00$ & $15,987.00$ & 21,024,00 & $11,783.00$ & $9,346,00$ & $10,903.00$ & $10,890.00$ & $7,845.00$ & $11,720.00$ \\
\hline Empresa 25 & $2,48.00$ & 912,00 & $2,833.00$ & $3,824,00$ & $3,942.00$ & $(841.00)$ & 332.00 & $4,207.00$ & $2,053.00$ & $1,540.00$ & 990.00 & 982.00 & $1,887.00$ \\
\hline Empresa 26 & $12,155.00$ & $10,689.00$ & $9,768.00$ & $13,649.00$ & $16,935.00$ & $11,889.00$ & $10,319.00$ & $9,616.00$ & $10,690,00$ & $10,173.00$ & $12,956.00$ & $18,731.00$ & $15,540.00$ \\
\hline
\end{tabular}

(continúa) 


\section{(continuación)}

\begin{tabular}{|c|c|c|c|c|c|c|c|c|c|c|c|c|c|}
\hline Utilidad Operativa(En miles de S/.) & 12015 & $|1| 2015$ & III 2015 & IV 2015 & 12016 & |II 2016 & III 2016 & IV 2016 & 12017 & $\mid 12017$ & III 2017 & IV 2017 & 12018 \\
\hline Empresa 27 & $13,419.00$ & $13,660.00$ & $14,133.00$ & $14,612.00$ & $16,822.00$ & $18,118.00$ & $18,733.00$ & $20,520.00$ & $19,017.00$ & $17,870.00$ & $16,974.00$ & $24,731.00$ & $25,021.00$ \\
\hline Empresa 28 & $30,652.00$ & $25,440.00$ & $26,315.00$ & $67,403.00$ & $34,997.00$ & $26,253.00$ & $29,696.00$ & $67,725.00$ & $40,839.00$ & $33,365.00$ & $35,036.00$ & $82,766.00$ & $45,303.00$ \\
\hline Empresa 29 & $17,020.00$ & $53,430.00$ & $35,706.00$ & $104,791.00$ & $19,072.00$ & $57,839.00$ & $44,987.00$ & $98,920.00$ & $(2,086.00)$ & $76,327.00$ & $29,091.00$ & $105,132.00$ & $31,954.00$ \\
\hline Empresa 30 & $5,089.00$ & $4,490.00$ & $5,704.00$ & $5,434.00$ & $2,533.00$ & $4,875.00$ & $7,122.00$ & $8,328.00$ & $6,001.00$ & $9,068.00$ & $10,395.00$ & $10,258.00$ & $9,641.00$ \\
\hline Empresa 31 & $81,138.00$ & $74,956.00$ & $105,937.00$ & $110,137.00$ & $99,624.00$ & $91,893.00$ & $74,526.00$ & $126,952.00$ & $112,102.00$ & $96,948.00$ & $73,777.00$ & $51,405.00$ & $66,350.00$ \\
\hline Empresa 32 & $65,692.00$ & $70,600.00$ & $30,312.00$ & $54,807.00$ & $113,078.00$ & $265,779.00$ & $53,915.00$ & $98,561.00$ & $127,084.00$ & $61,781.00$ & $48,437.00$ & $123,309.00$ & $103,308.00$ \\
\hline Empresa 33 & $57,468.00$ & $59,248.00$ & $107,273.00$ & $66,899.00$ & $87,096.00$ & $88,885.00$ & $117,744.00$ & $119,936.00$ & $98,145.00$ & $119,376.00$ & $126,447.00$ & $135,834.00$ & $103,153.00$ \\
\hline Empresa 34 & $29,910.00$ & $29,629.00$ & $24,820.00$ & $8,229.00$ & $5,581.00$ & $7,590.00$ & $7,540.00$ & $8,044.00$ & $8,406.00$ & $9,721.00$ & $7,804.00$ & $12,415.00$ & $15,352.00$ \\
\hline Empresa 35 & $15,545.00$ & $10,123.00$ & $8,379.00$ & $12,304.00$ & $9,401.00$ & $9,25.00$ & $(135.00)$ & $5,259.00$ & $13,826.00$ & $9,245.00$ & $4,551.00$ & $9,398.00$ & $1,964.00$ \\
\hline Empresa 36 & $1,193.00$ & $(1,511.00)$ & $3,326.00$ & $5,245.00$ & $1,217.00$ & $7,085.00$ & $7,085.00$ & $7,085.00$ & $(1,422.00)$ & $(3,967.00)$ & $(3,967.00)$ & $(20,385.00)$ & $(4,148.00)$ \\
\hline Empresa 37 & $6,767.00$ & $7,877.00$ & $9,393.00$ & $5,245.00$ & $6,437.00$ & $4,947.00$ & $3,433.00$ & $1,646.00$ & $1,710.00$ & $4,985.00$ & $3,577.00$ & $1,177.00$ &. \\
\hline resa 38 & 374.00 & $(1,956.00)$ & $(2,451.00)$ & $(14,027.00)$ & $(1,494.00)$ & $1,803.00$ & $1,013.00$ & $(1,018.00)$ & 874.00 & $1,255.00$ & $(1,344,00)$ & 653.00 & 653.00 \\
\hline Empresa 39 & 240.00 & $3,976.00$ & $(2,025.00)$ & 705.00 & $3,833.00$ & $3,944.00$ & $(4,404.00)$ & $6,769.00$ & $6,587.00$ & $1,959.00$ & $7,586.00$ & $(1,449.00)$ & $1,593.00$ \\
\hline Empresa 40 & $4,580.00$ & $4,801.00$ & $4,428.00$ & $8,143.00$ & $5,182.00$ & $6,789.00$ & $6,683.00$ & $7,990.00$ & $5,974.00$ & $7,986.00$ & $7,177.00$ & $7,871.00$ & $5,238.00$ \\
\hline Empresa 41 & $(654.00)$ & 671.00 & $1,581.00$ & $4,465.00$ & $1,174.00$ & $1,535.00$ & $2,405.00$ & $4,717.00$ & $1,267.00$ & $1,535.00$ & $2,405.00$ & $4,717.00$ & $2,255.00$ \\
\hline Empresa 42 & $(4,026.00)$ & $8,749.00$ & $3,259.00$ & $(3,395.00)$ & $6,196.00$ & $2,055.00$ & $2,514.00$ & $(12,007.00)$ & $20,722.00$ & $11,432.00$ & $11,444.00$ & $(18,697.00)$ & $4,770.00$ \\
\hline Empresa 43 & $(11,497,00)$ & $84,381.00$ & $3,794.00$ & $30,597.00$ & $17,709.00$ & $(29,170.00)$ & $13,900.00$ & $(12,530.00)$ & $16,345.00$ & $51,683.00$ & $(21,481.00)$ & $(2,658.00)$ & $8,040.00$ \\
\hline Empresa 44 & $11,321.00$ & $12,753.00$ & $13,841.00$ & $16,331.00$ & $24,701.00$ & $15,049.00$ & $15,631.00$ & $21,057.00$ & $18,428.00$ & $3,406.00$ & $18,049.00$ & $28,683.00$ & $15,296.00$ \\
\hline Empresa 45 & $19,141.00$ & $19,523.00$ & $19,138.00$ & $11,428.00$ & $36,015.00$ & $25,785.00$ & $26,566.00$ & $13,511.00$ & $31,459.00$ & $24,810.00$ & $23,643.00$ & $1,117.00$ & $33,382.00$ \\
\hline Empresa 46 & $3,400.00$ & $3,350.00$ & $5,236.00$ & $5,105.00$ & $7,532.00$ & $4,784.00$ & $4,031.00$ & $4,416.00$ & $4,101.00$ & $3,204.00$ & $2,100.00$ & $(1,021.00)$ & $2,495.00$ \\
\hline Empresa 47 & 16.00 & $2,201.00$ & $1,291.00$ & 622.00 & 675.00 & 230.00 & 492.00 & 720.00 & 669.00 & 775.00 & 314.00 & 827.00 & $1,029.00$ \\
\hline Empresa 48 & $(5,954.00)$ & $(5,029.00)$ & $(6,441.00)$ & $(3,129.00)$ & $(3,696.00)$ & $1,204.00$ & $6,658.00$ & $33,201.00$ & $15,675.00$ & $12,735.00$ & $29,950.00$ & $64,552.00$ & $32,235.00$ \\
\hline Empresa 49 & $(1,727.00)$ & $1,263.00$ & $(10,587.00)$ & $1,200.00$ & $8,527.00$ & $11,541.00$ & $20,691.00$ & $20,559.00$ & $20,632.00$ & $29,324.00$ & $21,001.00$ & $44,611.00$ & $31,316.00$ \\
\hline Empresa 50 & $27,431.00$ & $25,552.00$ & $43,259.00$ & $43,520.00$ & $67,351.00$ & $71,741.00$ & $72,444.00$ & $51,979.00$ & $60,562.00$ & $76,026.00$ & $84,576.00$ & $77,487.00$ & $84,022.00$ \\
\hline Empresa 51 & $11,558.00$ & $10,195.00$ & $10,824.00$ & $10,443.00$ & $17,166.00$ & $15,113.00$ & $8,047.00$ & $4,325.00$ & $9,818.00$ & $13,848.00$ & $4,086.00$ & $(554.00)$ & $4,290.00$ \\
\hline Empresa 52 & $(2,058.00)$ & $(7,176.00)$ & $(8,809.00)$ & $(18,712.00)$ & $12,503.00$ & $37,838.00$ & $30,716.00$ & $9,169.00$ & $6,823.00$ & $8,335.00$ & $27,136.00$ & $23,090.00$ & $18,859.00$ \\
\hline Empresa 53 & $19,939.00$ & $7,668.00$ & $18,028.00$ & $(4,064.00)$ & $15,598.00$ & $9,100.00$ & $11,662.00$ & $8,239.00$ & $8,587.00$ & $6,862.00$ & $17,999.00$ & $24,538.00$ & 396.00 \\
\hline
\end{tabular}

Fuente: Superintendencia de Banca, Seguros y AFP, SBS (2001-2017). Elaboración Propia

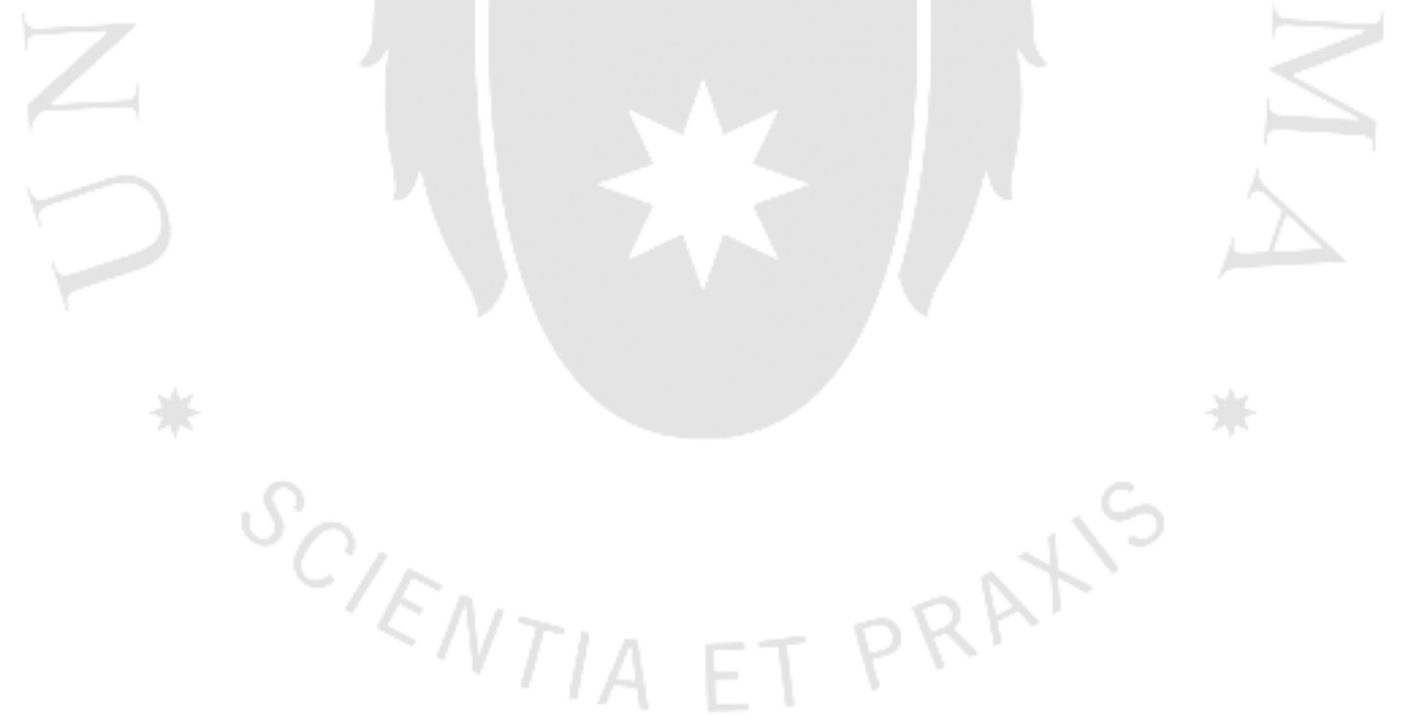




\section{Anexo 3: Diferencia de Cambio neto de empresas listadas en la SMV, 2015 - 2018}

\begin{tabular}{|c|c|c|c|c|c|c|c|c|c|c|c|c|c|}
\hline Diferencia de Cambio Neto (En miles de S/.) & 12015 & III 2015 & III 2015 & IV 2015 & 12016 & III 2016 & IIII 2016 & IV 2016 & 12017 & |11 2017 & ||112017 & IN 2017 & 12018 \\
\hline Empresa 1 & $(107,842.00)$ & $(72,326.00)$ & $(33,863.00)$ & 0) $(163,547.00)$ & $63,439.00$ & $(20,460.00)$ & $(78,799.00)$ & $18,181.00$ & $85,239.00$ & $5,457.00$ & $8,275.00$ & \begin{tabular}{|r|r|}
0 & $16,535.00$ \\
\end{tabular} & $11,136.00$ \\
\hline Empresa 2 & 269.00 & $(796.00)$ & $(1,136.00)$ & 636.00 & $(595.00)$ & $(835.00)$ & $(1,879.00)$ & $(760.00)$ & $2,066.00$ & $(428.00)$ & $(461.00)$ & 399.00 & $(1,380.00)$ \\
\hline Empresa 3 & $(11,396.00)$ & $(10,752.00)$ & $3,932.00$ & $(16,573.00)$ & $4,315.00$ & $1,940.00$ & $(7,613.00)$ & 755.00 & $5,731.00$ & $(426.00)$ & $(618.00)$ & $1,155.00$ & 489.00 \\
\hline Empresa 4 & $(9,657.00)$ & $(7,429.00)$ & $(2,109.00)$ & $(11,817.00)$ & 111.00 & 794.00 & 631.00 & $(3,330.00)$ & $(2,002.00)$ & 0) $\quad(1,410.00)$ & 318.00 & \begin{tabular}{|l|l|}
0 & $(1,843.00)$ \\
\end{tabular} & $(405.00)$ \\
\hline Empresa 5 & $(26,642.00)$ & $(17,950.00)$ & $(5,670.00)$ & $(2,849.00)$ & \begin{tabular}{|l|}
$(8,617.00)$ \\
\end{tabular} & $5,009.00$ & $1,396.00$ & $(856,00)$ & $1,950.00$ & $(579.00)$ & 303.00 & 95.00 & $1,307.00$ \\
\hline Empresa 6 & $2,654.00$ & $1,674.00$ & $1,888.00$ & $3,315.00$ & $(697.00)$ & $1,530.00$ & $1,735.00$ & $(2,534.00)$ & $(2,620.00)$ & 179.00 & 238.00 & $(566.00)$ & 427.00 \\
\hline Empresa 7 & $5,147.00$ & 554.00 & $1,694.00$ & $4,975.00$ & $(2,598.00)$ & $(606.00)$ & $3,500.00$ & $(1,590.00)$ & $(1,044.00)$ & (918.00) & 114.00 & 229.00 & $(323.00)$ \\
\hline Empresa 8 & $5,074.00$ & $(544.00)$ & 414.00 & $2,020.00$ & $(1,630.00)$ & $1,729.00$ & $(2,953.00)$ & $(68.00)$ & 109.00 & $(480.00)$ & 59.00 & $(333.00)$ & $(229.00)$ \\
\hline Empresa 9 & 84.00 & 14.00 & 11.00 & 45.00 & $(7.00)$ & $(1.00)$ & 18.00 & $(7.00)$ & $(22.00)$ & $(2.00)$ & 1.00 & $(4.00)$ & $(5.00)$ \\
\hline Empresa 10 & $(715.00)$ & $(528.00)$ & $(436.00)$ & 301.00 & $(686.00)$ & $(476.00)$ & $(21.00)$ & $(623.00)$ & $(389.00)$ & $(413.00)$ & $(234.00)$ & $(430.00)$ & $(137.00)$ \\
\hline Empresa 11 & $(738.00)$ & $(574.00)$ & $(289.00)$ & $(1,205.00)$ & 558.00 & 212.00 & $(697.00)$ & 270.00 & 705.00 & $(41.00)$ & $(155.00)$ & 142.00 & 130.00 \\
\hline Empresa 12 & $(5,979.00)$ & $(4,440.00)$ & $(2,054.00)$ & $(8,787.00)$ & $3,290.00$ & $1,199.00$ & $(3,767.00)$ & 568.00 & $1,512.00$ & $(31.00)$ & $(176.00)$ & 218.00 & 157.00 \\
\hline Empresa 13 & $(1,679.00)$ & $(1,479.00)$ & $(1,053.00)$ & $(2,969.00)$ & 503.00 & 441.00 & $(1,991.00)$ & 420.00 & $1,852.00$ & $(539.00)$ & $(236.00)$ & 313.00 & 343.00 \\
\hline Empresa 14 & $(2,083.00)$ & $(2,278.00)$ & $(1,762.00)$ & $(6,548.00)$ & $3,342.00$ & 543.00 & $(2,653.00)$ & 672.00 & $1,901.00$ & $(223.00)$ & $(448.00)$ & 251.00 & 279.00 \\
\hline Empresa 15 & $(3,495.00)$ & $(3,234.00)$ & $(780.00)$ & $(4,936.00)$ & $2,481.00$ & 223.00 & $(2,424.00)$ & 627.00 & $2,842.00$ & $(338.00)$ & $(273.00)$ & 474.00 & 360.00 \\
\hline Empresa 16 & $(16,252.00)$ & $(13,213.00)$ & $(12,745.00)$ & $(30,307.00)$ & $11,986.00$ & $3,308.00$ & $(13,291.00)$ & $2,830.00$ & $14,191.00$ & $(739.00)$ & $(898.00)$ & 182.00 & $1,437.00$ \\
\hline Empresa 17 & $(6,478.00)$ & $(5,083.00)$ & $(4,365.00)$ & $(11,117.00)$ & $2,948.00$ & $2,738.00$ & $(5,407.00)$ & 985.00 & $5,431.00$ & $(636.00)$ & $(1,042.00)$ & 668.00 & $1,050.00$ \\
\hline Empresa 18 & $(36,621.00)$ & $(24,073.00)$ & $(11,496.00)$ & (2) $\quad(23,347.00)$ & $11,307.00$ & $(44.00)$ & $(14,062.00)$ & $7,006.00$ & $15,552.00$ & $(922.00)$ & $(2,238.00)$ & 0) $\quad(6,593.00)$ & $1,282.00$ \\
\hline Empresa 19 & $(5,334.00)$ & $(4,822.00)$ & $(1,370.00)$ & $2,989.00$ & $(1,263.00)$ & $(922.00)$ & 776.00 & $(556.00)$ & $(759.00)$ & 27.00 & $(9.00)$ & $(116.00)$ & $(72.00)$ \\
\hline Empresa 20 & 384.00 & $\begin{array}{l}408.00 \\
\end{array}$ & 329.00 & $1,339.00$ & $(667.00)$ & $(272.00)$ & 703.00 & $(299.00)$ & $(713.00)$ & 32.00 & 81.00 & $(169.00)$ & $(77.00)$ \\
\hline Empresa 21 & 265.00 & $(620.00)$ & $(298.00)$ & $1,033.00$ & $1,042.00$ & 748.00 & $(1,813.00)$ & 526.00 & 829.00 & $(338.00)$ & 125.00 & 717.00 & $(644.00)$ \\
\hline Empresa 22 & $(13.00)$ & $(102.00)$ & $(106.00)$ & $(364.00)$ & 117.00 & 16.00 & $(296.00)$ & 110.00 & 83.00 & $(57.00)$ & $(92.00)$ & 26.00 & $(27.00)$ \\
\hline Empresa 23 & $(1,257.00)$ & $(1770.00)$ & $(387.00)$ & 221.00 & $(655.00)$ & $(383.00)$ & 83.00 & $(412.00)$ & (595.00) & $(74.00)$ & $(64.00)$ & $(318.00)$ & $(100.00)$ \\
\hline Empresa 24 & 511.00 & 590.00 & 139.00 & 739.00 & $(329.00)$ & $(47.00)$ & 608.00 & $(232.00)$ & $(482.00)$ & 290.00 & $(226.00)$ & $(41.00)$ & $(47.00)$ \\
\hline Empresa 25 & 4.00 & 653.00 & 381.00 & $1,926.00$ & $(1,741.00)$ & $(480.00)$ & $1,074.00$ & 86.00 & $(321.00)$ & $(280.00)$ & 62.00 & 119.00 & $(325.00)$ \\
\hline Empresa 26 & $(854.00)$ & $(4660.00)$ & $(140.00)$ & $(482.00)$ & $(266.00)$ & 203.00 & $(365.00)$ & 67.00 & 27.00 & 238.00 & $(88.00)$ & $(7.00)$ & 15.00 \\
\hline
\end{tabular}


(continuación)

\begin{tabular}{|c|c|c|c|c|c|c|c|c|c|c|c|c|c|}
\hline Diferencia de Cambio Neto (En miles de SI.) & 12015 & $\| 12015$ & III 2015 & IN 2015 & 12016 & $\| 2016$ & $\mid 112016$ & IN 2016 & 12017 & $\| 12017$ & $\mid 112017$ & | 2017 & 2018 \\
\hline Empresa 27 & $(2,955.00)$ & $(739,000)$ & $1,357.00$ & $(3,855.00)$ & 657.00 & 61900 & $(1,126,000)$ & 971.00 & $2,153.00$ & $(1,233,00)$ & 803.00 & 636.00 & $(144,0)$ \\
\hline Empresa 28 & $(17,823,00)$ & $(12,056,00)$ & $6,927.00$ & $(11,525.00)$ & $5,760.00$ & $2,302.00$ & $(5,550,00)$ & $2,915.00$ & $6,294.00$ & 240.00 & $(20.00)$ & 330.00 & $(9.00)$ \\
\hline Empresa 29 & $(1,351.00)$ & $(330.000)$ & 784.00 & $(1,608.00)$ & 510,00 & $1,512.00$ & $(2,107,00)$ & $2,181.00$ & $2,696,00$ & $(225.00)$ & $(477.00)$ & 456.00 & $2,833.00$ \\
\hline Empresa 30 & (998.00) & $(614,00)$ & $(374,00)$ & $(1,189.00)$ & 106.00 & 282.00 & (533.00) & 231.00 & 792.00 & (228.00) & $(122.00)$ & 159.00 & 177.00 \\
\hline Empresa 31 & $(1,210000)$ & $(523.000$ & 459.00 & 533.00 & (585.00) & $(108.00)$ & $2,607.00$ & 327.00 & 654.00 & 269.00 & 996.00 & 237.00 & 181.00 \\
\hline Empress 32 & $(62,340,00)$ & $(43,634,00)$ & $(23,956.00)$ & $(99,430.00)$ & 19,371100 & $11,315.00$ & $(24,366.00)$ & $9,184.00$ & $25,433.00$ & $(2,471.00)$ & $(2,691.00)$ & $4,917,00$ & $3,839.00$ \\
\hline Empresa 33 & $(5,551.00)$ & $(13,891.00)$ & $1,688.00$ & $4,915.00$ & $(2,533.00)$ & 24,00 & $(5,411.00)$ & $(4,790,00)$ & $(7,706.00)$ & 80.00 & $(897.00)$ & 740.00 & $(1,217,00)$ \\
\hline Empresa 34 & $(23,998.00)$ & $(15,542,00)$ & $(10,498.00)$ & $5,486.00$ & $(1,803.00)$ & $(1,755,00)$ & $2,266.00$ & $(114.00)$ & $(3,555,00)$ & 100.00 & 332.00 & $(608.00)$ & $(375.00)$ \\
\hline Empresa 35 & 813.00 & 1,91000 & 1,121:100 & 3,301.:00 & $1,125.00$ & 26,00 & $2,516.00$ & $(666.00)$ & $(2,973.00)$ & 296.00 & 872.00 & $(613.00)$ & $(737.00)$ \\
\hline Empresa 36 & $(398.00)$ & $(1,5111,00)$ & $(1,52,00)$ & $(4,224,00)$ & $1,793.00$ & 650.00 & 6550.00 & 650.00 & $2,276.00$ & (223.00) & $(231.00)$ & 460.00 & 247.00 \\
\hline Empresa 37 & $(171.00)$ & $(40.00)$ & $(54,00)$ & $(1010.00)$ & 230.00 & $(106.00)$ & 93.00 & 194,00 & 114.00 & $(119.00)$ & 283.00 & $(334.00)$ & \\
\hline Empresa 38 & $(963.00)$ & $(508.00)$ & $\mid 109.00) \mid$ & $(20,000)$ & $(1,633.00)$ & 136.00 & $(310.00) \mid$ & 79.00 & 450.00 & $(6.00)$ & $(15.00)$ & 6.00 & 15.00 \\
\hline Empresa 39 & $(658.00)$ & 8.00 & $(35.00)$ & 90100 & $(1,680,00)$ & $(967.00)$ & (574.00) & $(1,279.00)$ & $(993.00)$ & $(2,599,00)$ & 1,472:00 & 19.00 & 199.00 \\
\hline Empresa 40 & . & $(524.00)$ & 123.00 & 380.00 & $(54,00)$ & (218.00) & (2233.00) & $(123.00)$ & $(198.00)$ & $(161.00)$ & $(130.00)$ & $(225.00)$ & $(14100)$ \\
\hline Empresa 41 & 64.00 & $(9.00)$ & 7.00 & 19.00 & $(180.00)$ & $(147.00)$ & 8.00 & $(53.00)$ & $(137.00)$ & 147.00 & 8.00 & $(53.00)$ & $(77,00)$ \\
\hline Empresa 42 & $(65.00)$ & 241.00 & $1,073.00$ & $(887.00)$ & $(377,00)$ & 293.00 & $(51400)$ & $2,660.00$ & $(11,00)$ & $(375.00)$ & $(307.00)$ & $(209.00)$ & (1100.00) \\
\hline Empresa 43 & $(11,30400)$ & $(6,917,00)$ & $(2,552,00)$ & $(13,456,00)$ & $5,413.00$ & $3,806.00$ & $(12,725.00)$ & 4,402200 & $11,399.00$ & $(1,957,00)$ & $(1,179.00)$ & $1,497.00$ & 780,000 \\
\hline Empresa 44 & $(513.00)$ & (271.00) & $(116.00)$ & $(10.00)$ & $(342.00)$ & 575.00 & 7880.0 & (238.00) & 353.0 & 37.00 & 69.00 & $(146.00)$ & $(960.00)$ \\
\hline Empresa 45 & $(7,867.00)$ & $(4,755.00)$ & $(1,274,00)$ & $11,613.00$ & 96.00 & $1,233.00$ & $(177.00)$ & 84.00 & $1,704,00$ & $(90,00)$ & 3,148.00 & $(510.00)$ & 276.00 \\
\hline Empresa 40 & $(752.00)$ & $(913.00)$ & $(2,131.00)$ & $(1,363,00)$ & 115.00 & 155.00 & 54.00 & 286.00 & 275.00 & $(19.00)$ & $(87.00)$ & 131.00 & 55.00 \\
\hline Empresa 47 & $(350.00)$ & $(207.00)$ & $(8.00)$ & $(18.00)$ & $(13,00)$ & $(66100)$ & $(194.00)$ & 10.00 & 8.00 & 24,00 & $(16.00)$ & 1.00 & $(29.00)$ \\
\hline Empresa 48 & 2,228.00 & $1,056.00$ & 670.00 & $1,922.00$ & $(1,110,00)$ & $(830.00)$ & $2,041.00$ & $(1,255.00)$ & $(3,980.00)$ & 144.00 & 346.00 & $(1,520,000)$ & $(901.00)$ \\
\hline Empresa 49 & $(2,379.00)$ & $(1,916,0,0)$ & (992:00) & $(4,5680.00)$ & $1,7112,00$ & 694,00 & $(2,247.00)$ & 373.00 & 1,451.00 & $(249.00)$ & $(279.00)$ & $(612.00)$ & $(157.00)$ \\
\hline Empresa 50 & $(5,275.00)$ & $(4,177,00)$ & $(2,233.00)$ & $(3,835.00)$ & $2,707.00$ & 494.00 & $(4,139.00)$ & $1,195.00$ & $3,578.00$ & $(372.00)$ & $(476,00)$ & 907.00 & 688.00 \\
\hline Empresa 51 & 265.00 & 620.00 & 172.00 & $1,886.00$ & $(853.00)$ & $(933.00)$ & $1,286.00$ & (223.00) & $(1,24,400)$ & 226.00 & 56.0 & $(664,00)$ & $(288.00)$ \\
\hline Empresa 52 & 140.00 & 1,561.00 & (981:00) & $(1,326.00)$ & $5,131.00$ & $(2,024,00)$ & $(1,741,00)$ & 439.00 & $1,156.00$ & $1,737.00$ & $(1,801.00)$ & 46.00 & 234.00 \\
\hline Empresa 53 & $(1,889,00)$ & $8,045.00$ & $1,214,00$ & $(467.00)$ & $2,117.00$ & 872.00 & $2,260.00$ & $2,085.00$ & $2,096.00$ & $1,022,00$ & $1,972.00$ & 980.00 & $1,252,00$ \\
\hline
\end{tabular}

Fuente: Superintendencia de Mercado de Valores, SMV (2015-2018). Elaboración Propia

\section{Anexo 4: Beneficio Económico de un Forward}

\begin{tabular}{|c|lc|}
\hline Tipo de Cambio & \multicolumn{2}{|c|}{ Utilidad } \\
\hline 3.60 & S/ & $161,290.32$ \\
\hline 3.50 & S/ & $129,032.26$ \\
\hline 3.40 & S/ & $96,774.19$ \\
\hline 3.30 & S/ & $64,516.13$ \\
\hline 3.20 & S/ & $32,258.06$ \\
\hline 3.10 & S/ & - \\
\hline 3.00 & S/ & $-32,258.06$ \\
\hline 2.90 & S/ & $-64,516.13$ \\
\hline 2.80 & S/ & $-96,774.19$ \\
\hline 2.70 & S/ $-129,032.26$ \\
\hline 2.60 & S/ $-161,290.32$ \\
\hline
\end{tabular}

Fuente: Elaboración Propia (2018) 